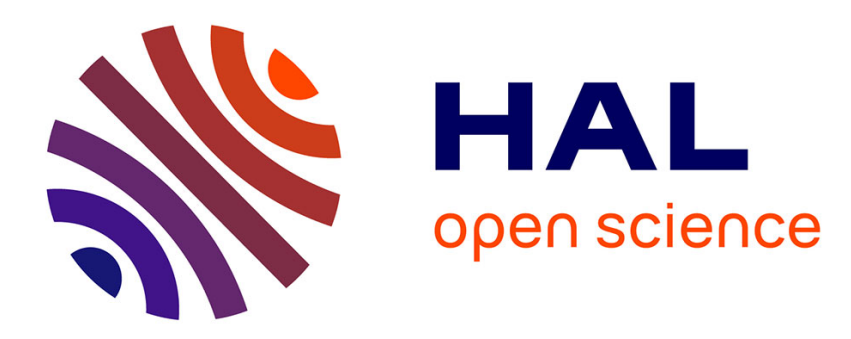

\title{
Potential of restoration of gravel-sand pits for bats
}

Christian Kerbiriou, Marion Parisot-Laprun, Jean François Julien

\section{To cite this version:}

Christian Kerbiriou, Marion Parisot-Laprun, Jean François Julien. Potential of restoration of gravelsand pits for bats. Ecological Engineering, 2018, 110, pp.137-145. 10.1016/j.ecoleng.2017.11.013 . hal-02554197

\section{HAL Id: hal-02554197 \\ https://hal.science/hal-02554197}

Submitted on 25 Apr 2020

HAL is a multi-disciplinary open access archive for the deposit and dissemination of scientific research documents, whether they are published or not. The documents may come from teaching and research institutions in France or abroad, or from public or private research centers.
L'archive ouverte pluridisciplinaire HAL, est destinée au dépôt et à la diffusion de documents scientifiques de niveau recherche, publiés ou non, émanant des établissements d'enseignement et de recherche français ou étrangers, des laboratoires publics ou privés. 


\section{Potential of restoration of gravel-sand pits for Bats}

2

3 Christian Kerbiriou ${ }^{1}$, Marion Parisot-Laprun ${ }^{2}$, Jean François Julien ${ }^{1}$

Concarneau, France

${ }^{2}$ ROSELIERE, 9 rue Basse, 77130, MISY-SUR-YONNE,

Corresponding author: Christian Kerbiriou, email : kerbiriou@ @mhn.fr

\section{Keywords}

gravel-sand pit; restoration of quarries; bat activity; bat community; wetland creation

\section{Abstract} due to ecosystems removal or topography alterations caused by exploitation. we selected external data from 76 sites of the French Bat Monitoring. We analysed the relative attractiveness of 17 habitats and 5 gravel-sand pit operating statuses (before of water and these habitats are among the most favorable for numerous bats species. In land-use pressure for bats. However, only quarries which had been rehabilitated for more than 10 years exhibited

Université, National Natural History Museum, Station marine, Place de la croix, 29900

Restoration management of quarries is one of the major tasks in global restoration ecology due to the magnitude of impacts link with extraction activities and the potential conservation value of these post-industrial sites. However, identifying a target to reach can be challenging as ecological issues can be numerous and post-exploitation state can differ from the original

Here, we assess the restoration potential of gravel-sand pits for Bats, a targeted group for conservation, using data from 21 gravel-sand pits monitored by the ROSELIERE scheme and quarrying, during quarrying, rehabilitation post-quarrying younger than 5 years, rehabilitation post-quarrying between 5 and 10 years and, finally, rehabilitation post-quarrying older than 10 years). We paid close attention to comparison between gravel-sand pits states and aquatic habitats, because the restoration process in the gravel-sand pits studied often leads to bodies addition, we focus our comparisons on arable land because new gravel-sand pit settlements are usually planned on such agricultural land and furthermore because it represents the major

We found that bat activity in gravel-sand pit displays a range comparable to what is observed in numerous habitats, though it does appear both slightly lower than in bodies of water and greater than arable land. Bat activity appears increasing during the gravel-sand pit life's cycle. significantly greater bat activity than observed in the four other gravel-sand pit states. Our 
results, highlight the length of time required to detect obvious changes in the attractiveness of site being rehabilitated and the magnitude of the gap between the current state and the target (i.e. aquatic habitat). Such results should be take into account when sizing offsetting measures of quarries.

\section{Introduction}

Mining activities (steel industries, coal mining, rock or gravel sand extraction) have affected about $1 \%$ of the land worldwide (Walker 1999). These post-industrial sites represent an increasing component of many landscapes and regions (Tropeck et al. 2010) and there is currently an urgent need to solve problems related to ecological restoration of affected regions (Š́álek 2012). After closing, most of these mining sites and quarries became neglected due to their decrease in economic value (Dekoninck et al. 2010). The original ecosystems have been removed, the original topography has been significantly changed and the previous ecological function has been irreversibly disrupted (Milgrom 2008). Spontaneous succession in those abandoned quarries resulted in a biodiversity pool that is significantly different from the original and surrounding habitats due to the dissimilarity between the physical and chemical substrate properties of the original and new soils (Dekoninck et al. 2010; Tischew \& Kirmer 2007). However, the opinion on these post-mining sites has changed among conservationists as natural recovery occurring in these sites may sometime result in the creation of biodiversity refuges, particularly in human-exploited regions (Tropeck et al. 2010). Quarries are periodically disturbed and offer early successional stage, with extreme abiotic conditions leading to xerophilous open or oligotrophic habitats (Krauss et al. 2009; Novak \& Prach 2003). However similar conditions have become rare in human-exploited regions, because agriculture intensification processes contribute to increase the use of fertilizers, that in turn lead to eutrophication of soil and water and indirectly contribute to abandonment of marginal unproductive lands. This, in turn, promotes middle phase of succession, which is also favored by intensive forestry (i.e. fuelwood and shortening of cycle Bouget et al. 2012). In addition, many human actions induce control of natural perturbations (i.e. channeling of rivers, fire regime...etc.) in such a way that specialized species dependent on early successional stage and sparsely vegetated habitats are among the most threatened in many regions (Morris et al. 1994; Hoekstra et al. 2005; Wenzel et al. 2006). Literature is, therefore, quite abundant on the conservation potential of quarry sites for vascular plants (Bizoux et al. 2004; Shu et al. 2005; Tropeck et al. 2010; Wheater \& Cullen 1997), spiders (Tropek \& Konvicka 2008; Tropeck et al. 2010), odonata (Harabis 2016; Tichanek \& Tropek 2015), orthoptera (Tropeck et al. 2010), 
coleoptera (Brändle et al. 2000), butterflies (Benes et al. 2003; Tropeck et al. 2010), wild bees (Krauss et al. 2009), ants (Dekoninck et al. 2010), amphibians (Dolezalova et al. 2012; Vojar et al. 2016) and birds (Šálek 2012). In addition to conservation policies focused on creating protected areas, it is increasingly argued that restoration of degraded areas must be undertaken in order to achieve worldwide ambitious targets (Aichi Biodiversity Targets) such as bringing close to zero the rate of loss of natural habitats. Based on the potential conservation value of these post-industrial sites, restoration management of quarries is now one of the major tasks in global restoration ecology (Tischew \& Kirmer 2007). One particularly important issue is the quantification of the roles of the various intrinsic, environmental and management factors on restoration success. In this context, several studies focus on the benefits of active restoration achieved by human intervention through reclamation works versus passive restoration where environmental stressors are removed and secondary succession takes place naturally. (see Brändle et al. 2000; Prach et al. 2011; Šálek 2012; Tropek \& Konvicka 2008).

Proper evaluation of restoration success requires first a standardized definition of success, though. Despite this pressing need, there still are no general and broadly accepted success criteria for restoration of quarries. This stems from several reasons: (i) original ecosystems have often been totally removed and newly hydrographic, physical and chemical conditions are so different that biodiversity pool can hardly return to a state close to the initial one, (ii) ecosystems before gravel sand extraction are rarely described and pristine ecosystems references are not easy to identify in some countries with long history of human footprint, (iii) quarries under restoration process are in a very dynamic state, (iv) there are rarely clearly defined biodiversity targets for quarries in conservation policies-strategies (i.e. which state or taxa to reach and promote). Therefore, restoration attempts may set goals that are too idealistic or based on incorrect assumptions of the state before human impacts (Nilsson et al. 2007). Indeed, as expected, the majority of studies dealing with biodiversity restoration within quarries did not clearly identify a target to reach. In addition, strong feedbacks between biotic factors and the physical environment can alter the efficacy of restoration management (Suding et al. 2004). Studies indicates that some degraded systems are resilient to traditional restoration efforts owing to constraints such as drastic changes of biogeochemical processes, changes in landscape connectivity, loss of native species pools, shifts in species dominance, invasion by exotics (Suding et al. 2004). Here, we focus on gravel-sand pits, a type of mining activities, which impact the original topography. After end of operating such quarries are colonized by body of water due to the massive extraction of sand and gravel of old riverbed and the water table. While a return to the original topography is thus not an option, the target 
state identified is aquatic habitat. Such spaces are then dedicated for public recreation facilities or for nature conservation but never return to some original land uses such as agriculture land.

Moreover, the great majority of studies that monitored biodiversity along successional stages in quarries rarely used external standardized references to assess comparisons between the biodiversity present within quarries and other habitats (see Bonifazi et al. 2003; Brändle et al. 2000; Dekoninck et al. 2010; Dolezalova et al. 2012; Krauss et al. 2009; Milgrom 2008; Novák \& Konvička 2006; Novák \& Prach 2010; Prach et al. 2013; Tropek et al. 2010; Tichanek \& Tropek 2015; Vojar et al. 2016; Yuan et al. 2006; Zhang \& Chu 2013), for the few studies that used explicit external references see: Benes et al. 2003; Khater et al. 2003; Tropek \& Konvicka 2008. External references (i.e. biodiversity states assessments on sites without quarry activity or outside of restoration process) usage allows, however, unbiased evaluation of the conservation value of quarries for biodiversity. What's more, it enables the definition of objective goals and thus impartial assessment of restoration success. In this way, we mobilize biodiversity data in quarries, using ROSELIERE scheme and we use independent dataset provide by VIGIE NATURE a national biodiversity monitoring scheme based on citizen science for provide an external reference. ROSELIERE (http://programmeroseliere.fr/node/21), is a biodiversity monitoring scheme focused on evaluating biodiversity dynamics in French gravel-sand pits, implemented since 2006. The main goals of the ROSELIERE program are (i) to assess the level of biodiversity in a large number of quarries nationwide (ii) assess the success of restoration programs of gravel-sand pits (iii) understand the basic processes that promote or reduce the conservation effectiveness of these restoration programs. ROSELIERE currently aims, thus, to monitor 12 taxonomic groups (birds, bats, amphibians, aquatic macro-invertebrates, butterfly, plants....) and is based on protocols consistent with national monitoring.

Measuring restoration at the community level is particularly tough, due to the great variability inherent in most natural communities and may require a focus on restoration of community function (e.g., trophic structure) rather than a focus on the restoration of a particular species (Palmer et al. 1977). Here we propose to focus on bat taxa, because this group and microchiropterans particularly are long live species and act as important biodiversity indicators as their population trends reflect those of lower trophic level species thus tracking the biodiversity response to anthropogenic pressures (Jones et al., 2009). Furthermore, several studies have highlighted their value in terms of providing ecosystem services (Kunz et al., 2011), such as pest control (Cleveland et al., 2006) seed dispersal 
(Medellin \& Gaona; 1999; Kelm et al., 2008) and pollination (Flemming et al., 2009). We measure bat activity using acoustic recorder, this metric based on bat echolocation is a diversity index, which directly include trophic function, because bats that hunt for flying insect, use echolocation to detect, identify, and localize prey (Schnitzler \& Kalko 2001). Indeed bat activity is used by academics researchers to investigate differential use of habitat by bats (Sherwin et al. 2000). Additionally, from a conservationist point of view, bats are a group of interest, because they are increasingly threatened worldwide (Mickleburgh et al., 2002). An important part of European bat species (40\%) have a poor conservation status much of their range (Barova \& streit 2014) because of various pressures, such as the loss of suitable foraging habitats (Walsh \& Harris 1996), agricultural practices that use toxic pesticides (Swanepoel et al. 1999, Wickramasinghe et al. 2004), emerging infectious diseases (Frick et al. 2010), urbanisation (Loeb et al., 2009), forest management (O’Donnell 2000) and roost destruction and disturbance (Mitchell-Jones et al. 2007). In response to these pressures, answers in terms of protection have been implemented: all Europeans bats are legally protected in European countries through national or European laws (Council Directive 1992, Convention on Migratory Species (CMS 1985-2008), and Agreement on the conservation of Populations of European Bats). In addition to species protection, $31 \%$ of European bat species are target species for the designation of Natura 2000 conservation areas (Barova \& streit 2014). To our knowledge, however, and despite this established role as valuable indicator, this particular group has never been studied in the context of quarry restoration.

Considering that relative abundance, diversity or success of restoration are relative states, we compared bat activity measures on gravel-sand pits sites (before operating, during quarrying or in rehabilitated sites) to bat activity measures on the main habitats present in France using data provided by VIGIE NATURE (http://vigienature.mnhn.fr/) and its dedicated survey of bat population (the French Bat Monitoring Program, FBMP). We paid close attention to comparison between gravel-sand pits states and aquatic habitats, because the restoration process in the gravel-sand pits studied often leads to bodies of water and these habitats are among the most favorable for numerous bats species. We also focus comparisons between gravel-sand pits states and arable land because newly gravel-sand pit settlements are usually planned on such agricultural land. Finally, we hypothesize that bat activity and mean communities diversity index based on bat activity will increase with timespan after beginning of rehabilitation. 


\section{Methods}

\subsection{Study Area}

The study was conducted in 21 gravel-sand pits. A significant portion of sites $(n=19)$ is comprised from the original launch area of the ROSELIERE program: the Bassée, an alluvial plain of the Seine located 90km south east from Paris, France. Two other sites were added to the network, all in the Atlantic and Continental biogeographical area (Figure 1). After decommission, the rehabilitation mainly leads to an ecological vocation with facilities favorable to the wildlife. These gravel-sand pits mainly evolved from bare soil ( $73 \%$ of sites sampled during quarrying) to bodies of water (due to the natural rise of the water table resulting from the sand extraction, $47 \%$ of sampled points $>10$ years after operating). At the level of the gravel-sand pit, the surface of the piece of water, representing an average of $42 \%$ of the total pit area. A spontaneous succession process occurs, leading to the installation of an afforestation on terrestrial areas (15\% of sampled points $>10$ years after operating). Some sites also include meadows being managed by grazing or mowing. Our sampled points in gravel-sand pits included a variety of vegetation types, we believe it provides a detailed picture of the current existing gravel-sand pits states, with its known bias toward more bushy and wooded vegetation for gravel-sand pits sampled long time after operating (see Appendix A). According to the type of quarries studied (gravel-sand pits in alluvial context), sampled points were often very close to aquatic habitats (mean average distance to water $202 \mathrm{~m} \pm 68$ (SE). In addition to these gravel-sand pit sites, we selected external data from 76 sites of the French Bat Monitoring Program (FBMP; Kerbiriou et al. 2010) located in the same biogeographical area (Figure 1) excluding Alpine region and the Mediterranean region, which host very different communities of bats (Dietz et al. 2009), with the aim of providing a measure of bat activity levels in gravel-sand pits (before and during quarrying or in rehabilitated sites) in comparison to a set of habitats reference. The FBMP sampling design consists of a randomly selected, $2 \mathrm{~km}$-sided, square, within which ten points are chosen by the observer. Such a sampling design resulted in a survey of habitats that are quite representative of those at the French scale $\left(\mathrm{R}^{2}=0.95\right)$. One to five points were sampled in gravel-sand pit sites depending on the site size (mean: $4.4 \pm 0.3$ ). Due to the type of studied quarries (gravelsand pit in an alluvial context), sampled points were often very close to aquatic habitats. Whatever the site considered, points were spaced out by 200 meters and placed among the quarry's main habitats. A total of 93 efficient points were sampled in gravel-sand pits and 724 for the FBMP (Table 1) 


\subsection{Bat Sampling}

207

208

209

210

\subsubsection{Acoustic recording}

We use bat activity measures, an approach widely used by researchers working for environmental consulting firms, government agencies (Adams et al. 2012, for example during evaluation of development projects) or academics researchers to investigate differential use of habitat by bats (Russo \& Jones 2003; Azam et al. 2016). Gravel-sand pits sites were sampled between 2009 and 2013 following a standardized echolocation recordings protocol similar to the one designed for the French Bat Monitoring Program (FMBP, 2012), from which we used data collected from 2006 to 2013.

For both ROSELIERE and FMBP programs, bat calls were detected using a Tranquility Transect Bat detector (Courtpan Design Ltd, UK) and recorded over 6 minutes. In each plot, echolocation recordings were carried out during two visits corresponding to bats activity peaks: first, during the $15^{\text {th }}$ June to $31^{\text {st }}$ July timespan, during which females are expected to give birth and feed their offspring; second, during the $15^{\text {th }}$ August to $30^{\text {st }}$ September timespan, during which youngs are flying. All points of any given site were sampled during the same night. The observers begin their sampling thirty minutes after dusk, in the same order for each visit (from season to season, and from year to year). Thus this sampling occurred during the bat activity peak that begins 30 minutes after sunset and spans less than 3 hours (Roche et al. 2005). Observers sampled bats only when weather conditions were favourable (no rain, temperature higher than $12^{\circ} \mathrm{C}$ and wind speed less than $5 \mathrm{~m} / \mathrm{sec}$ ). For more details on protocol see Appendix A. The whole data set is composed by 711 records in gravel-sand pits and 2263 records from the FBMP.

\subsubsection{Bats identification and bat activity measures}

Species calls were identified using Syrinx software version 2.6 (Burt, 2006) for spectrogram analyses. For the ROSELIERE data, identifications were made by the authors. For the national data, identifications were made by voluntary observers and then validated by Museum's scientists (CK, JFJ, Yves Bas). Identification was made at the species level except for two genera: Plecotus and Myotis, for more details on bats identification see Appendix B.

As it is impossible to distinguish individual bats from echolocation calls, we measured, on each sampled site, bat activity, defined as a mean number of bat pass per species (a bat pass corresponds to a trigger of the bat detector in time expansion). The response variables were (i) species abundance of foraging calls ( $n=7$ taxa), (ii) the total abundance of foraging calls, (iii) 
species richness and (iv) Community Habitat specialization index (CSI). We calculated (CSI) as the arithmetic mean of the species habitat specialization index (SSI) of the detected species weighted by their abundance (see Appendix C for more details about the assessment of CSI and SSI). Note that the CSI and the total abundance of foraging calls are two metrics that could be potentially biased by an abundant specie.

\subsubsection{Sampled points characteristics}

Gravel-sand pit points were grouped into five categories (Table 1), according to the state of extraction or rehabilitation: before operating (B.O.), during quarrying (D.Q.) and three categories of rehabilitation according to the elapsed time after operating ( $<5$ years; 5 years $<<10$ years and $>10$ years).

In order to assess the difference between gravel-sand pits and common habitats present in France, we collected habitat characteristics in a radius of $100 \mathrm{~m}$ around the 724 points provided by the FBMP (Table 1), using a detailed hierarchical habitat classification (Kerbiriou et al. 2010) relatively similar to the one used for bird-habitat classification system (Crick, 1992) and with the first classes consistent with Corine Land Cover classification. Based on a minimum number of replicate per habitat category $(n=24)$, we selected 17 habitat types (Table 1). Among these habitats, we paid a special attention to (i) bodies of water category (5.1.2, Corine Land Cover category) because they are the targeted state and (ii) cereal crops, (2.1.1, Corine Land Cover category) because newly gravel-sand pit settlements are usually planned on such agricultural land and furthermore because arable land represents the major land-use pressures for bats (Azam et al. 2016).

\subsection{Data Analysis}

\subsubsection{Relative abundance of bat activity in gravel sand pit compared to the main habitats} present in France

In a first assessment of gravel-sand pits as foraging/commuting habitats for bats, we compared bat activity (i.e. response variable) in the 93 sample points in gravel-sand pits (ROSELIERE) with 724 points from the FBMP database, respectively to each habitat. Bat activity is either species abundance, total abundance, richness and CSI.

We assessed potential differences in bat activity among habitats (i.e. common habitats for FBMP points and the five categories of uses for gravel-sand pits) using Generalized Mixed Models (GLMM; package GLMMADMB, Bolker 2015). The protocol is performed only when weather conditions are generally favourable, however, we took into account temperature 
as a co-variable because we assumed that bat activity might be affected by weather conditions (Ciechanowski et al. 2007). Because each visit covered two different periods of the bat life cycle and might have influenced bat activity we also included a season variable. In addition, as yearly changes in bat abundance can be expected, we included a year effect (year as a factorial variable). According to the hierarchical structure of our sampling design (same sites sampled year to year and several points within a same site), we treated the site variable as a random effect, while considering the other explanatory variables (season, temperature, year, habitats) as fixed effects (Zuur et al. 2009). We did not included local vegetation characteristics in modelling because it is obviously correlated with time elapsed after operating (see Appendix A). In addition, we hypothesized that close points, even if their habitat differs, are likely to have a similar bat population density due to similar climatic conditions or large-scale landscape compositions. Thus, to account for spatial autocorrelation, we added an autocovariate (i.e., a distance-weighted function of neighboring response values) with the autocov dist function in R (package spdep, Bivand R. et al. 2011). Thus our statistical models were structured in the following way:

$[$ Bat activity] $\sim$ habitat + season + temperature + year + autocovariate $+1 \mid$ Site

Where bat activity could be bat specific abundance $(n=8)$ or total abundance, richness and CSI. Habitat is a categorical variable with 22 categories (including 5 states of gravel-sand pit and the 17 main habitat present in France see Table 1).

Due to the nature of the response variable (bat count) and potential over dispersion we performed, for each species, GLMMs with a Poisson error distribution, a negative binomial distribution and zero inflation models with a negative binomial or Poisson error distribution (Zuur et al. 2009). Choice and validation of model were based on a multi-criteria approach following Zuur et al. (2009) looking at potential pattern in residual and AIC value and pseudo R-square. When the model did not fit well, we transformed the response variable (i.e. bat activity abundance) in a presence/absence variable and then used a binomial error distribution. Models selected are shown in Appendix D. Finally, in order to test pairwise comparisons between habitats (and particularly bodies of water, the habitat reference), we ran a Tukey post hoc tests (package lsmeans, Lenth R. 2015).

\subsubsection{Variation of bat activity across gravel sand pit life's cycle}


Using similar modelling approaches (GLMMs with negative binomial error distribution), as previously, we focused our analysis on variation of the global effect, independently of the considered species, between the five gravel-sand pit states (before operating, during quarrying and three rehabilitation categories depending on the elapsed time after the quarry stopped operating). Thus, we added species identity as a random effect to account for differences in abundance between species (Jiguet et al. 2010, Pavón-Jordán et al. 2017, Pellissier et al. 2013). Our statistical models were structured in the following way:

[Bat activity] $\sim$ gravel-sand pits state + season + temperature + year + autocovariate $+1 \mid$ Site +1 species

Where bat activity is bat specific abundance.

Effects of each variable were evaluated using a type II ANOVA with an F-test.

\section{Results}

\subsection{Species contacted}

The FBMP network ( $\mathrm{n}=724$ sites) yielded 12385 contacts for 17 bats taxa while ROSELIERE network of gravel-sand pits ( $\mathrm{n}=93$ sites) yielded 1698 contacts for 12 bats taxa. The taxa which occurred sufficiently to allow assessing bat activity at the level of the 22 habitat classes (i.e. the 5 gravel-sand pit states and the 17 habitat classes from FBMP) where were: $P$. pipistrellus (59\%), P. kuhlii (8\%), P. nathusii (4\%), N. noctula (6\%), N. leisleri (8\%), E. serotinus (5\%) and Myotis ssp (10\%), details of species occurrence per habitats are provided in Appendix E.

\subsection{Relative abundance of bat activity in gravel-sand pits compared to France wide} representative habitats

As expected, bat activity varied among habitats and between species (Fig. 2,). While the average of bat activity appeared globally lower in gravel-sand pit states than in bodies of water (i.e. the reference habitat) for most species, we did detect relatively few significant differences, mainly due to great variance around estimate (see Fig. 2 and Appendix F). The notably significant differences (Tukey post hoc tests with a significance level alpha $=0.05$, see Appendix F) in bat activity were detected for $P$. pipistrellus and Myotis ssp, for which richness and total of abundance of foraging calls activity were greater in bodies of water than in pre-operating sites. In addition, richness was greater in sites rehabilitated more than 10 years ago than before operating. Myotis ssp abundance on arable land were significantly lower than on gravel-sand pits rehabilitated more than 5 years ago. Similarly, P. nathusii and $N$. 
leisleri abundance in gravel-sand pits rehabilitated more than 10 years ago was also significantly greater than arable land.

\subsection{Variation of bat activity across the gravel-sand pit life's cycle}

When focusing on the global effect of gravel-sand pits states, regardless of the considered species, we showed that this variable influences significantly bat activity (Table 2). While bat activity appears increasing during the gravel-sand pit life's cycle (Fig. 3), only gravel-sandpits which rehabilitation is older than 10 years display bat activity greater than the four other gravel-sand pit states (Tukey post hoc tests with a significance level alpha $=0.05$ ). This result is not qualitatively influenced by $P$. pipistrellus (i.e. the most abundant species) see Appendix G.

\section{Discussion}

\subsection{Bats in gravel-sand pits}

This study shows that several bats inhabit gravel-sand pit sites, regardless of the quarrying life cycle, in particular, even during quarrying extraction. P. pipistrellus is clearly the species exhibiting far from the other a high level of activity, this pattern is a constant among studies dealing with bat activities in Northern and Western Europe (Wickramasinghe et al. 2003, Roche et al. 2011, Newson et al. 2015). However, contacted species are mainly relatively common species, while rare or threatened species (i.e. species listed on the Annexe II of the EU Habitats Directive (EEC 1992) or in the French IUCN red list) were almost never contacted. Only two contacts of a rare species (Myotis emarginatus) were recorded in two different gravel-sand pits which had been rehabilitated more than 10 years ago. The quasiabsence of rare or threatened species could be linked to (i) the nature of sampled sites: indeed, neither ROSELIERE or FBMP programs focused on remarkable sites such as reserves or pristine areas; (ii) ROSELIERE's main sampled region, Île-de-France, undergoes a lot of anthropogenic pressures and is not the most welcoming French region for biodiversity; (iii) the protocol used, which is based on short time recording (i.e. 6 minutes). This characteristic of the protocol was designed to allow observers to sample several sites during the same early night. With the recent arrival on the market of new generation of bat detector-recorder, we could consider recording throughout the entire night (see Azam et al. 2015; Stahlschmidt, \& Brühl 2012) and thus expect increasing the probability of contacting rare species. We will be able to utilize, in future studies, data from the recent third protocol of the FBMP (2012) which is based on such technology (Bas et al. 2015). In addition, we recommend in the future, when 
a quarry would be involve in a long term ecological survey to promote also the implantation of a FBMP sites survey close to this quarries site.

When looking at the average of bat activity in gravel-sand pit states (i.e. reflecting their interest in term of foraging areas), this parameter displays a range comparable to what is observed in numerous habitats but appears lower than in bodies of water (which could be considered as the target to reach), though appears greater than in arable land (i.e. the major land-use pressure and currently often the habitat type where gravel-sand pits are planned to be exploited). We did, however, detect relatively few significant differences due to great variance around estimate and low occurrence of some species. This great variance could be linked to (i) the short time recording of this protocol, (ii) the nature of the response variable, i.e. bat activity measure, which is naturally characterized by great variance (Barlow 2015), or (iii) differences between sites. This latest non-exclusive hypothesis should be explored to allow for identifying intrinsic or surrounding site characteristics that could explain lower or greater abundance for a similar gravel-sand pit life cycle category, then permitting the exploration of ways to maximize bat abundance.

Our findings concerning (i) the globally low levels of bat activity in pre-operating sites (Fig. 2) and (ii) the significantly lower bat activity for P. pipistrellus and Myotis ssp, richness and total abundance of foraging in pre-operating sites compared to what's observed in bodies of water (Table S5), indicate that sites chosen to develop extracting activity seem to globally follow the mitigation hierarchy to avoid and/or limit the negative effects of project development on biodiversity (e.g., avoid development in biodiversity hotspot, in areas where rare or threatened species occur (BBOP 2012; Fox \& Nino-Murcia 2005; Regnery et al. 2013)).

\subsection{Variation of bat activity during the life cycle of quarrying}

Bat activity appears increasing during the gravel-sand pit life's cycle (Fig. 3), but only gravelsand pits which had been rehabilitated for more than 10 years exhibited greater bat activity than observed in the four other gravel-sand pit states, highlighting the length of time required to detect obvious changes in the attractiveness of site being rehabilitated. A number of studies also highlight the positive influence of aged quarries on species richness, e.g. for birds (Š́álek 2012) or terrestrial plants (Prach et al. 2011, 2013), while other find a negative effect, for butterflies (Benes et al. 2003). Brändle et al. 2000 did not detect any age effect on dwelling beetle richness, neither did Krauss et al. (2009) on wild bees richness although they tested an age gradient of over 120 years, habitat areas being the best predictor. These contrasted 
findings among taxa are probably linked to their habitat requirement, bees and butterflies' communities are probably favored by open habitats such as grassland present in early stage of succession while birds and bats need more wooded habitats occurring in late succession. An overview of sites disturbed by mining in the past 50 years in Czech Republic (Prach et al. 2011) indicates that the time to more or less stabilized late vegetation usually occurred between 20 to 60 years (20 years for gravel-sand pits). In addition to spontaneous vegetation succession, the species colonization capacities and surrounding landscape must be taken into account. Flavenot et al. 2015 find that genetic diversity of toads population in quarries could be linked to the surrounding habitat structure. This structure present 60 years ago was determinant for Bufo bufo, while the effect was significant only for the habitat structure present 10 years ago for Bufo calamita, which is considered to be more dispersive than $B$. Bufo. It was also demonstrated that quarries can host pioneer habitat that promotes Bufo calamita.

\subsection{Conservation implications}

This study shows that (i) several bats inhabit gravel-sand pit sites, independently of the quarrying status, (ii) bat activity average on quarries has the same order of magnitude than in numerous habitats but appears to be lower in gravel-sand pit stages than in bodies of water (i.e. the habitat that could be identified as a target to reach), and (iii) time elapsed after quarry operations acts as a driver of bat activity. Thus this study highlights the conservation value of quarries as foraging areas for bats, but also the time delay required to detect significant increase in bat activity (>10years). In the framework of the mitigation hierarchy (BBOP 2012), the third step consists in conducting on-site or ex-situ restoration or rehabilitation to correct the negative impacts of the project. Time delay is then a key point: the greater the importance of time needed to recover, the more significant transient biodiversity losses will become. Such losses will likely result if human activity and its impacts are allowed to occur before offsetting measures are put in place. The most straightforward solution, however, is to require offsets to be effective before losses occur or as soon as possible after any impact is observed (Quétier et al. 2014). In the case of gravel-sand pits, the extraction site is often a mosaic of patches with different states and uses, and restoration begins immediately after the end of extraction on each patch. Therefore, disturbance is limited and species can colonize the area while another sector is exploited (principle of coordinated rehabilitation). As they generate new natural spaces (bodies of water or ponds, grasslands, shrubs and later woodlands...), rehabilitated areas offer hunting habitats for bats while extraction still occurs 
in the vicinity. Comparatively, the attractiveness of these areas is often all the more important that intensive agriculture was practiced on the site pre-extraction and that human pressure subsided and quiet is restored.

A possible solution to address the issue of conservation value that differs depending on taxa over the succession evolution (favorable in early stage for pioneers species or open habitat specialized species and favorable in late stage for species linked to more productive, mature habitat, or forest specialized species) could consist in clearly defining a target for a site (i.e. arbitrate the priority: which taxa should be favored according to the site stakes) and thus planning an adapted management. For example, if conservation of xerophilous butterflies is defined as the target to reach, preventing natural vegetation succession and planning to maintain or to restore patches of earlier-succession habitat could be enforced (Benes et al. 2003). Another solution would be to attempt to maintain a mosaic of different succession stages within sites, this solution could be more easily implemented when restoration is coordinated with extraction. This mosaic approach within site may depend on site size, indeed Krauss et al. (2009) underline that the major driver of bee richness was habitat area, this approach is thus probably not recommended for small sites.

A perspective in this research is now to identify the respective importance of intrinsic variables (i.e. vegetation structure, site size...etc.) and landscape variables (surrounding habitat, connectivity...etc.) that could increase the attractiveness of the sites.

\section{Appendix}

Detailed information on the French Bat Monitoring Program, count point protocol (Appendix A), Bats identifications (Appendix B), Assessment of habitat specialization species index and community specializations indices (Appendix C), Model selection for modelling bat activity between habitats (Appendix D), Appendix E: Average occurrence and bat activity among the different gravel-sand pit state and habitat (Appendix E), Pairwise comparisons between habitats (Appendix F), Impact of taking into account or not $P$. pipistrellus (i.e. the most abundant species) on assessment of age of gravel-sand pits restoration effect on relative importance of bat activity (Appendix G) are available online,.

\section{Acknowledgement}

This work was co-funded by French National Union of Quarrying and Materials Industries of Île-de-France (UNICEM IDF), French National Union of Aggregate Producers (UNPG), operators on extracting sites (A2C Granulats, CEMEX, GSM, Lafarge Granulats, Sables de 
Brévannes) and a naturalist NGO (Association des Naturalistes de la Vallée du Loing et du massif de Fontainebleau, ANVL). The authors certify that the funding source had no influence on the collection, analysis or interpretation of the data. The authors have declared that no competing interests exist. This program could not have been possible without the motivation and involvement of C. Parisot, initiator of the ROSELIERE program. We thank naturalists NGO (ANN, Atelier des territoires, AVEN du Grand Voyeux, CDPNE, CREN MidiPyrennées, CSNHN, FDC Haute-Garonne, FRAPNA Loire, GONm, Loiret Nature Environnement, LPO Aquitaine, LPO Isère, LPO PACA, LPO Sarthe, NaturAgora, SEPANSO Gironde, SEPANSO Landes, Seine-et-Marne Environnement) and engineering offices (Alfa Conseil, Sciences Environnement) involved in data collection in gravel-sand pit sites, and owners of rehabilitated sites (Water Agency of Seine-Normandie, Agence des Espaces Verts of Île-de-France, Department of Seine-et-Marne, Eau de Paris and Pro Natura Île-de-France). We deeply thank the voluntary observers who took part in the French Bat Monitoring Program, a large-scale survey which relies entirely on them. Finally, we thank C. Laprun for an earlier reading of our manuscript

\section{Legends of tables and figure}

Table 1. number of sampled points per state of quarrying or habitat and in bracket the number of data when years replicate are taken into account.

Table 2. Results of the modelling of bat activity's variation across gravel-sand pit life's cycle.

Figure 1. Map of the distribution in France of the sampled sites from the French Bat Monitoring Program (black square) and the gravel-sand pit sites of ROSELIERE program (white triangle)

Figure 2. Relative importance of bat activity (A: Pipistrellus pipistrellus, B: Pipistrellus kuhlii, C: Pipistrellus nathusii, D: Nyctalus noctula, E: Nyctalus leisleri, F: Eptesicus serotinus, G: Myotis ssp., H:Abundance ; I: Richness, J: Community Specialization Index) in gravel-sand pits (white barplot: before operating (B.O.), during quarrying (D.Q.), after operating ( $<5$ years), after operating ( 5 years $<<10$ years) and after operating ( $>10$ years $)$ ) compared to the main habitats present in France (black barplot : industrial, commercial and units (I.C.), residential urban area (R.U.), discontinuous artificial surfaces (D.A.), urban park (U.P.), vineyards and orchards (V.O.), arable land (A.L.), heterogeneous agricultural areas 
(H.A.), scrub and heathland (S.H.), dry grassland (D.G.), coniferous forest (C.F.), broadleaved forest (B.F.), mixed forest (M.F.), waterway (W.), small water courses (S.W.), large water courses (L.W.), ponds (P.), bodies of water (B.W.). Bat activity measures are abundance (i.e. number of bat pass per 6 minutes), except for E. serotinus, for whom it is the probability of contact per 6 minutes.

Figure 3. Relative importance of bat activity in gravel-sand pits

\section{Literature cited}

Adams, A.M., Jantzen, M.K., Hamilton, R.M., Fenton, M.B., 2012. Do you hear what I hear? Implications of detector selection for acoustic monitoring of bats. Methods Ecol. Evol. 3, 992-998.

Azam, C., Kerbiriou, C., Vernet, A. Julien, J.F., Bas, Y., Plichard, L., Maratrat, J., Le Viol, I., 2015. Is part-night lighting an efficient measure to limit the impacts of artificial lighting on bats? Global Change Biol; 21, 4333-4341.

Azam, C., Le Viol, I., Julien, J.F., Bas, Y., Kerbiriou, C., 2016. Disentangling the relative effect of light pollution, impervious surfaces and intensive agriculture on bat activity with a national-scale monitoring program. Landscape Ecol; 31(10), 2471-2483.

Barlow, K.E., Briggs, P.A., Haysom, K.A., Hutson, A.M., Lechiara, N.L., Racey, P.A., Walsh, A.L., Langton, S.D., 2015. Citizen science reveals trends in bat populations: The National Bat Monitoring Program in Great Britain, Biol. Conserv. 182, 14-26.

Barova, S., Streit A., (eds) 2014. Action plan for the conservation of the bat species In the european union 2014 - 2020. 2nd DRAFT VERSION - 24/02

Bas, Y., Kerbiriou, C., Jeliazkov, A., Le Viol, I., Julien, J.F., 2015. Large-scale decline of bats and bush-crickets revealed thanks to automatic acoustic monitoring scheme. 27th International congress for conservation biology. 2nd-6th August 2015, Montpellier, France.

BBOP, (Business and Biodiversity Offsets Programme). 2012. Biodiversity offset design handbook-updated. Available from http://bbop.forest-trends.org/guidelines/odh.pdf (accessed March 2017, BBOP Washington, D.C).

Benes, J., Kepka, P., Konvicka, M., 2003. Limestone quarries as refuges for European xerophilous butterflies. Conserv. Biol. 17, 1058-1069. 
Bizoux, J.P., Brevers, F., Meerts, P., Graitson, E., Mahy, G., 2004. Ecology and conservation of Belgian populations of Viola calaminaria, a metallophyte with a restricted geographic distribution. Belg. J. Bot. 137, 91-104.

Bonifazi, G., Cutaia, L., Massacci, P., Roselli, I., 2003. Monitoring of abandoned quarries by remote sensing and in situ surveying. Ecol. Model. 170(2-3), 213-218.

Bouget, C., Lassauce, A., Jonsell, M. 2012. Effects of fuelwood harvesting on biodiversity a review focused on the situation in Europe. Revue canadienne de recherche forestière, 42(8), 1421-1432.

Brändle, M., Durka, W., Altmoos, M., 2000. Diversity of surface dwelling beetle assemblages in open-cast lignite mines in Central Germany. Biodiver. Conserv. 9, 1297.

Burt, J., 2006. Syrinx a software for real time spectrographic recording, analysis and playback of sound. Available from http:/www.syrinxpc.com (accessed March 2017).

Crick, H.Q.P., 1992. A bird-habitat coding system for use in Britain and Ireland incorporating aspects of land-management and human activity. Bird Study 39, 1-12.

Cleveland, C.J., Betke, M., Federico, P., Frank, J.D., Hallam, T.G., Horn, J., López Juan, D., McCracken, G.F., Medellín, R.A., Moreno-Valdez, A., Sansone, C.G., Westbrook, J.K., Kunz, T.H., 2006. Economic value of the pest control service provided by Brazilian free-tailed bats in south-central Texas. Frontiers in Ecology and the Environment1 4(5), 238-243.

Ciechanowski, M., Zajac, T., Bilas, A., Dunajski, R., 2007. Spatiotemporal variation in activity of bat species differing in hunting tactics: effects of weather moonlight, food abundance, and structural clutter. Rev. Can. Zool. 85, 1249-1263.

Dekoninck, W., Hendrick, F., Dethier, M., Maelfait, J.P., 2010. Forest succession endangers the special ant fauna of abandoned quarries along the river Meuse (Wallonia, Belgium). Restor. Ecol. 18(5), 681-690.

Dietz C., von Helversen O., Nill D., 2009. Bats of Britain, Europe and Northwest Africa. London: A and C Black Publishers;

Dolezalova, J., Vojar, J., Smolova, D., Solsky, M., Kopecky, O., 2012. Technical reclamation and spontaneous succession produce different water habitats: A case study from Czech post-mining sites. Ecol. Eng. 43, 5-12.

European Economic Community (EEC). 1992. Council directive 92/43EEC of 21 May 1992 on the conservation of natural habitats and of wild fauna and flora. Official Journal L206, 7-50. 
FBMP, 2012, The protocols of the French Breeding Bird Survey and the Bat Survey are available from http://vigienature.mnhn.fr/page/protocole-pedestre (accessed March 2017, MNHN, Paris France).

Flavenot, S., Abdelkrim, J., Baguette, M., Coulon, A., 2015. Impact of quarrying on genetic diversity: an approach across landscapes and over time. Conserv. Genet. 16, 181-194.

Fleming T.H., Geiselman C., Kress W.J., 2009. The evolution of bat pollination: a phylogenetic perspective, Annals of Botany, 104(6), 1017-1043.Fox, J., Nino-Murcia, A., 2005. Status of species conservation banking in the United States. Conserv. Biol. 19, 996-1007.

Frick, W.F., Pollock, J.F., Hicks, A.C., Langwig, K.E., Reynolds, D.S., Turner, G.G. Butchkoski, C.M., Kunz, T.H., 2010. An Emerging Disease Causes Regional Population Collapse of a Common North American Bat Species. Science 5992, 679682.

Harabis, F., 2016. High diversity of odonates in post-mining areas: Meta-analysis uncovers potential pitfalls associated with the formation and management of valuable habitats. Ecol. Eng. 90, 438-446.

Hoekstra, J.M., Boucher, T.M., Ricketts, T.H., Roberts, C., 2005. Confronting a biome crisis: global disparities of habitat loss and protection. Ecol. Let. 8, 23-29.

Jones, G., Jacobs, D.S., Kunz, T.H., Willig, M.R., Racey, P.A., 2009. Carpenoctem: the importance of bats as bioindicators. Endangered Species Research 8, 93-115.

Jiguet, F., Devictor, V., Ottvall, R., van Turnhout, C., van der Jeugd, H., Lindström, A., 2010. Bird population trends are linearly affected by climate change along species thermal ranges. Proceedings of the Royal Society of London B 277, 3601-36078.

Kelm,D.H., Wiesner K.R., vonHelversen. O., 2008. Effects of artificial roosts for frugivorous bats on seed dispersal in a neotropical forest pasture mosaic. Conserv. Biol. 22, 733741.

Kerbiriou, C., Bas, Y., Dufrêne, L., Robert, A., Julien, J.F., 2010. Long term trends monitoring of bats, from biodiversity indicator production to species specialization assessment. Society for Conservation Biology. 24th Annual Meeting. 3 - 7 July, 2010, Edmonton, Alberta, Canada. Available from http://www.conbio.org/images/content_conferences/2010Abstracts.pdf (accessed March 2017)

Khater, C., Martin, A., Maillet, J., 2003. Spontaneous vegetation dynamics and restoration prospects for limestone quarries in Lebanon. Applied Vegetation Science 6, 199-204. 
Krauss, J., Alfert, T., Steffan-Dewenter, I., 2009. Habitat area but not habitat age determines wild bee richness in limestone quarries. J. Appl. Ecol. 46, 194-202.

Kunz, T.H., Fenton M.B. (eds.)., 2003. Bat ecology. University of Chicago Press, Chicago, $779 \mathrm{pp}$

Kunz T.H., Braun de Torrez E., Bauer D., Lobova T., Fleming, T.H., 2011. Ecosystem services provided by bats. Annals of the New York Academy of Sciences, 1223: 1-38.

Loeb, S., Christopher., J. P., Hall, S.T., 2009. Relationship between urbanization and bat community structure in national parks of the southeastern U.S. Urban Ecosystems 12, 197-214.

Medellin, R.A., Gaona, O., 1999. Seed Dispersal by Bats and Birds in Forest and Disturbed Habitats of Chiapas, Mexico1. Biotropica, 31, 478-485.

Mickleburgh, S.P., Hutson, A.M, Racey, P.A., 2002. A review of the global conservation status of bats. Oryx $36,18-34$.

Milgrom, T., 2008. Environmental aspects of rehabilitating abandoned quarries: Israel as a case study. Landscape Urban Plan. 87(3), 172-179.

Mitchell-Jones, A. J., Bihari, Z., Masing, M., Rodrigues, L. 2007. Protecting and managing underground sites for bats. EUROBATS Publication Series, 2: 1-38.

Morris, M.G., Thomas, J.A., Ward, L.K., Snazell, R.G., Pywell, R.F., Stevenson, M.J., Webb, N.R., 1994. Re-creation of Early-successional Stages for Threatened Butterflies - an Ecological Engineering Approach. J. Environ. Manage. 42(2), 119-135.

Newson, S.T., Evans, H.E., Gillings, S. 2015. A novel citizen science approach for large-scale standardised monitoring of bat activity and distribution, evaluated in eastern England. Biol. Cons. 191, 38-49.

Nilsson, C., Jansson, R., Malmqvist, B., Naiman, R.J. 2007. Restoring riverine landscapes: the challenge of identifying priorities, reference states, and techniques. Ecol. Soc.12(1), 16. [online] URL: http://www.ecologyandsociety.org/vol12/iss1/art16/

Novák, J., Prach, K., 2003. Vegetation succession in basalt quarries: pattern over a landscape scale. Appl. Veg. Sci. 6, 111-116.

Novák, J, Konvička, M., 2006. Proximity of valuable habitats affects succession patterns in abandoned quarries, Ecol. Eng. 26(2), 113-122.

Novák, N., Prach, K., 2010. Artificial sowing of endangered dry grassland species into disused basalt quarries. Flora - Morphology, Distribution, Functional Ecology of Plants 205(3), 179-183. 
O'Donnell, C.F.J. 2000. Conservation status and causes of decline of the threatened New Zealand long-tailed bat Chalinolobus tuberculatus (Chiroptera: Vespertilionidae). Mammal Review 30, 89-106.

Palmer, M.A., Ambrose, R.F., Poff, N.L. 1997. Ecological Theory and Community Restoration Ecology. Restoration Ecology 5, 291-300.

Pavón-Jordán D., Santangeli A., Lehikoinen A. 2017. Effects of flyway-wide weather conditions and breeding habitat on the breeding abundance of migratory boreal waterbirds. J. Avian Biol. 48: 988-996.

Pellissier V., Touroult J., Julliard R., Siblet J.P., Jiguet J. 2013. Assessing the Natura 2000 network with a common breeding birds survey. Animal Cons. 16, 566-574.

Prach, K., Řehounková, K., Řehounek, J., Konvalinková, J., 2011. Ecological restoration of central european mining sites: a summary of a multi-site analysis. Landscape Research 36(2), 263-268.

Prach, K., Lencová, K., Řehounková, K., Dvořáková, H., Jírová, A., Konvalinková, P., Mudrák, O., Novák, J., Trnková, R., 2013. Spontaneous vegetation succession at different central European mining sites: a comparison across seres. Environmental Science and Pollution Res. 20, 7680-7685.

Quétier, F., Regnery, B., Levrel, H., 2014. No net loss of biodiversity or paper offsets? A critical review of the French no net loss policy. Environ. Sci. Policy 38, 120-131.

Regnery, B., Couvet, D., Kerbiriou, C., 2013. Offset measures and development projects: the conservation of protected species under the EU Birds and Habitats Directives. Conserv. Biol. 27, 1335-1343

Roche, N., Catto, C., Langton, S., Aughney, T., Russ J., 2005. Development of a Car-Based Bat Monitoring Protocol for the Republic of Ireland. Irish Wildlife Manuals, No. 19. National Parks and Wildlife Service, Department of Environment, Heritage and Local Government, Dublin, Ireland.

Russo, D., Jones, G., 2003. Use of foraging habitats by bats in a Mediterranean area determined by acoustic surveys: conservation implications. Ecography 26, 197-209.

Šálek, M., 2012. Spontaneous succession on opencast mining sites: implications for bird biodiversity. J. Appl. Ecol. 49, 1417-1425.

Schnitzler H.U., Kalko E.K.V., 2001. Echolocation by insect-eating bats. BioScience 51(7), 557-569.

Sherwin, R.E., Gannon, W.L., Haymond, S., 2000. The efficacy of acoustic techniques to infer differential. Use of habitat by bats. Acta Chiropterol. 2,145-153. 
Stahlschmidt, P., Brühl, C.A., 2012. Bats as bioindicators - the need of a standardized method for acoustic bat activity surveys. Methods Ecol. Evol. 3, 503-508.

Shu, W.S., Ye, Z.H., Zhang, Z.Q., Lan, C.Y., Wong, M.H., 2005.Natural colonisation of plants on five lead/zinc mine tailings in Southern China. Restoration Ecology 13, 4960.

Suding K.N., Gross K.L., Houseman G.R., 2004. Alternative states and positive feedbacks in restoration ecology, Trends Ecol Evol , 19(1), 46-53.

Swanepoel, R.E., Racey P.A., Shore, R.F., Speakman, J.R. 1999. Energetic effects of sublethal exposure to lindane on pipistrelle bats (Pipistrellus pipistrellus). Environ. Pol. 104: 169-177.

Tichanek, F., Tropek, R.J., 2015. Conservation value of post-mining headwaters: drainage channels at a lignite spoil heap harbour threatened stream dragonflies. J. Insect Conserv. 19, 975.

Tischew, S., Kirmer, A., 2007. Implementation of basic studies in the ecological restoration of surface-mined land. Restor. Ecol. 15, 321-325.

Tropek, R., Konvicka, M., 2008. Can quarries supplement rare xeric habitats in a piedmont region? Spiders of the Blansky les Mts., Czech Republic. Land Degrad. Dev. 19, 104114.

Tropek, R., Kadlec, T., Karesova, P., Spitzer, L., Kocarek, P., Malenovsky, I., Banar, P., Tuf ,I.H., Hejda, M., Konvicka, M., 2010. Spontaneous succession in limestone quarries as an effective restoration tool for endangered arthropods and plants. J. Appl. Ecol. 47, $139-147$.

Vojar, J., Doležalová, J., Solský, M., Smolová, D., Kopecký, O., Kadlec, T., Knapp, M., 2016. Spontaneous succession on spoil banks supports amphibian diversity and abundance, Ecol. Eng. 90, 278-284.

Walker, L.R., 1999. Ecosystems of disturbed land. Elsevier, New York.

Walsh, A.L., Harris, S. 1996. Foraging habitat preference of vespertilionid bats in Britain. J. Appl. Ecol. 33, 508-518.

Wenzel, M., Schmitt, T., Weitzel, M., Seitz, A., 2006. The severe decline of butterflies on western German calcareous grasslands during the last 30 years: a conservation problem. Biol. Conserv. 128, 542-552.

Wheater C.P., Cullen, W.R., 1997. The flora and invertebrate fauna of abandoned limestone quarries in Derbyshire. Restor. Ecol. 5, 77-84. 
Wickramasinghe, L.P., Harris, S., Jones, G., Vaughan-Jennings, N. 2004. Abundance and species richness of nocturnal insects on organic and conventional farms: effects of agricultural intensification on bat foraging. Cons. Biol. 18, 1283-1292.

Yuan, J.G., Fang, W., Fan, L., Chen, Y., Wang, D.Q., Yang, Z.Y., 2006. Soil Formation and Vegetation Establishment on the Cliff Face of Abandoned Quarries in the Early Stages of Natural Colonization. Restor. Ecol. 14, 349-356.

Zhang, H., Zhuang, X. Chu, L.M., 2013. Plant Recruitment in Early Development Stages on Rehabilitated Quarries in Hong Kong. Restor. Ecol. 21, 166-173.

Zuur, A.F., Ieno, E.N., Walker, N., Saveliev, A.A., Smith, G.M., 2009. Mixed Effects Models and Extensions in Ecology with R. Statistics for Biology and Health. Springer, New York, USA, p. 574. 
Figure 1. Map of the distribution in France of the sampled sites from the French Bat Monitoring Program (black square) and the gravel-sand pit sites of ROSELIERE program (white triangle)

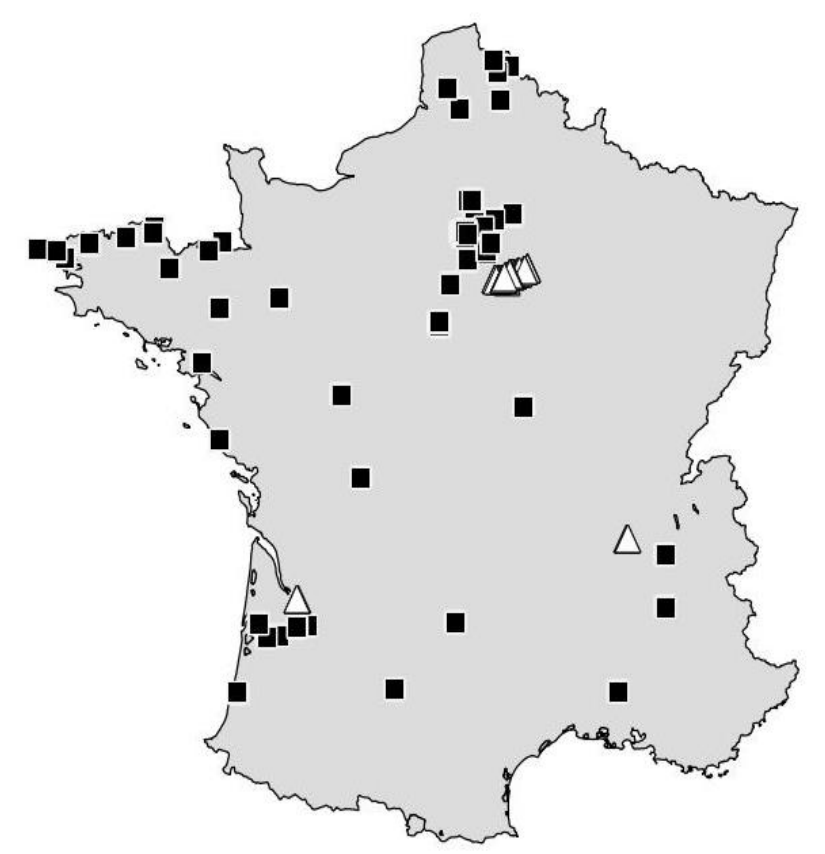

728

729

730

731

732

733

734

735

736

737

738

739

740

741

742

743

Figure 2. Relative importance of bat activity (A: Pipistrellus pipistrellus, B: Pipistrellus kuhlii, C: Pipistrellus nathusii, D: Nyctalus noctula, E: Nyctalus leisleri, F: Eptesicus serotinus, G: Myotis ssp., H:Abundance ; I: Richness, J: Community Specialization Index) in gravel-sand pits (white barplot: before operating (B.O.), during quarrying (D.Q.), after operating ( $<5$ years), after operating ( 5 years $<<10$ years) and after operating ( $>10$ years $)$ ) compared to the main habitats present in France (black barplot : industrial, commercial and units (I.C.), residential urban area (R.U.), discontinuous artificial surfaces (D.A.), urban park (U.P.), vineyards and orchards (V.O.), arable land (A.L.), heterogeneous agricultural areas (H.A.), scrub and heathland (S.H.), dry grassland (D.G.), coniferous forest (C.F.), broadleaved forest (B.F.), mixed forest (M.F.), waterway (W.), small water courses (S.W.), large water courses (L.W.), ponds (P.), bodies of water (B.W.). Bat activity measures are abundance (i.e. number of bat pass per 6 minutes), except for E. serotinus, for whom it is the probability of contact per 6 minutes. 
Figure 2.

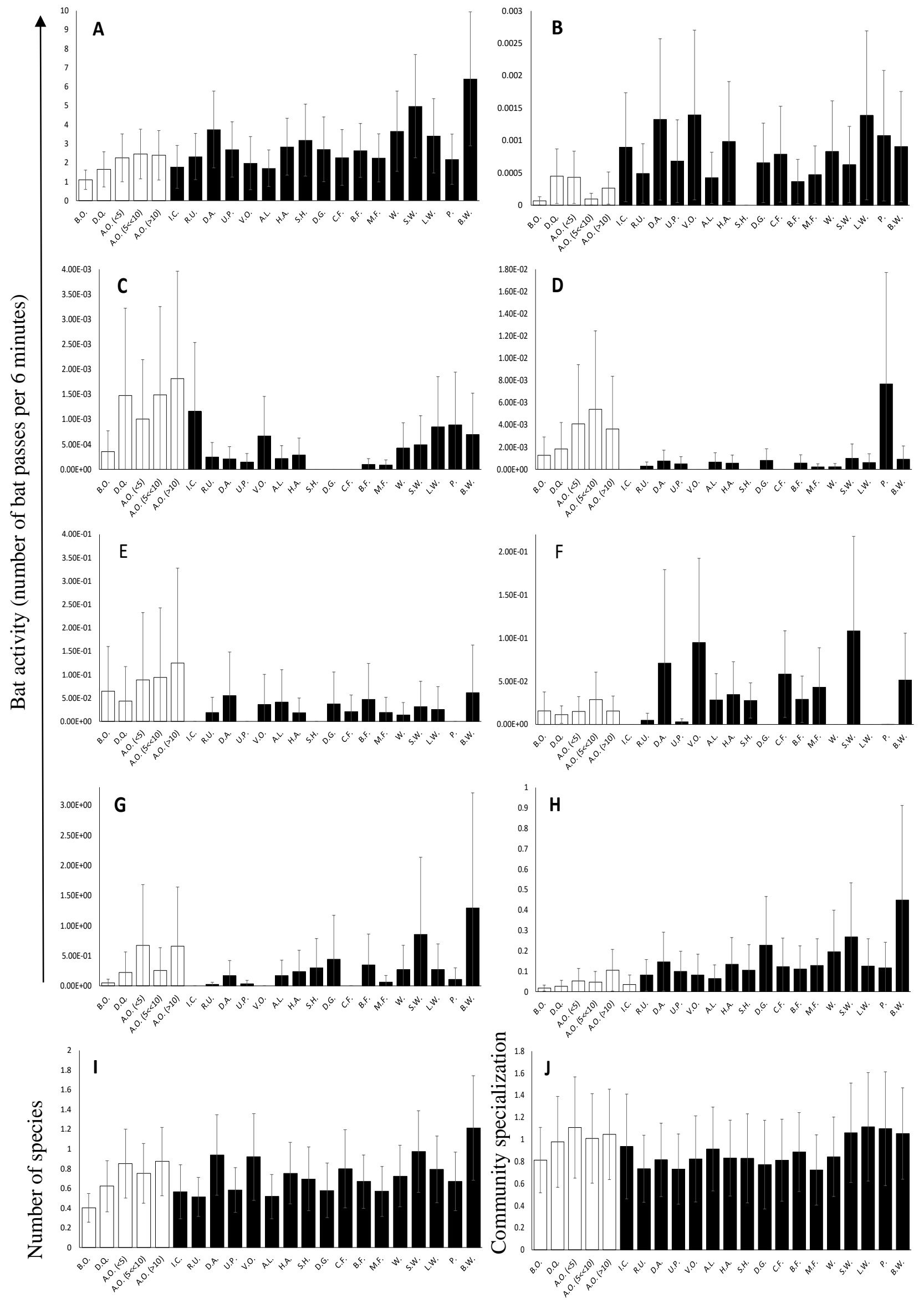


Figure 3. Relative importance of bat activity in gravel-sand pits

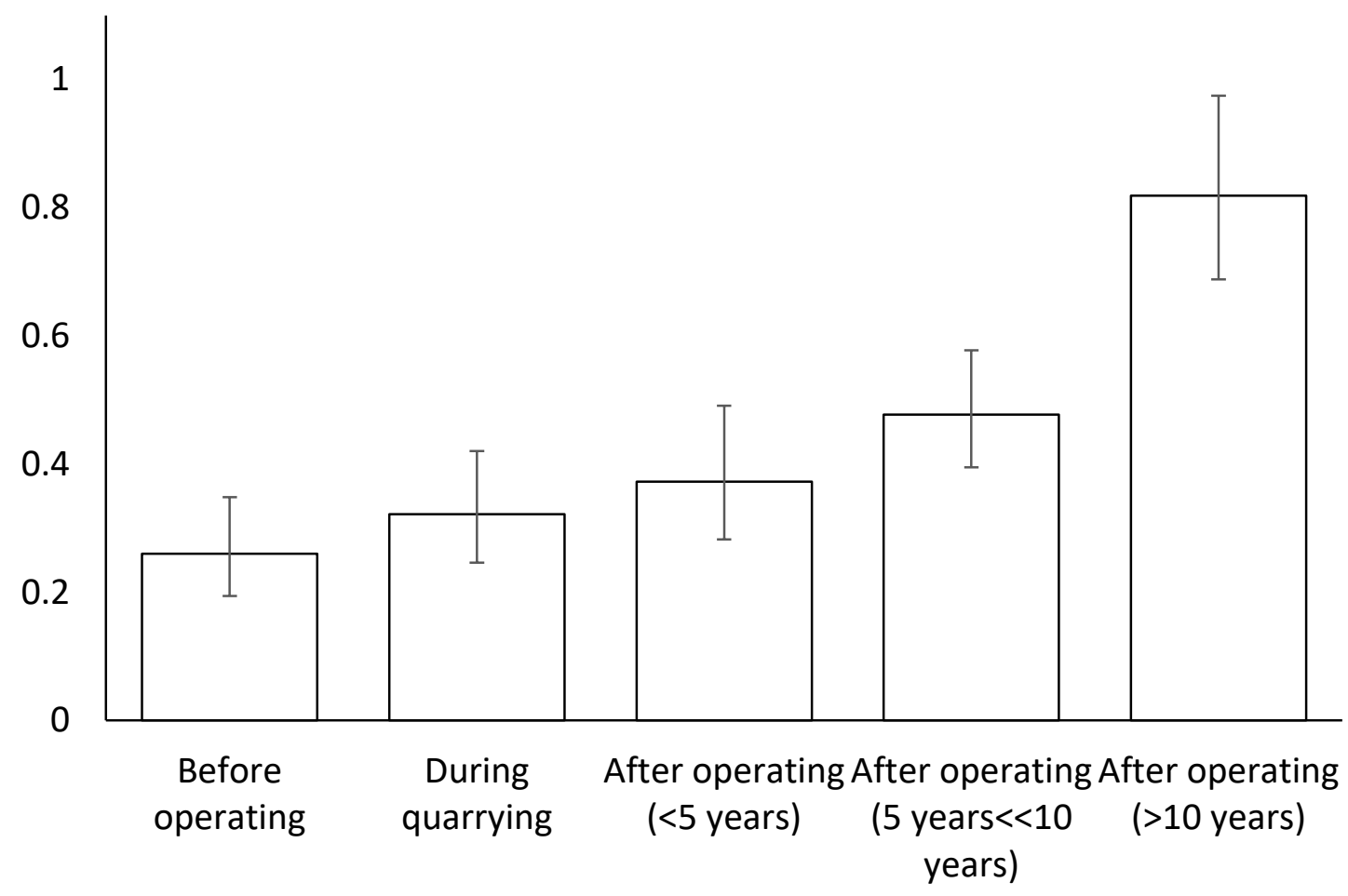


Table 1. number of sampled points per state of quarrying or habitat and in bracket the number of data when years replicate are taken into account.

Gravel-sand pit point $\quad$ FBMP points

\begin{tabular}{lc}
\hline Before operating (B.O.) & $21(158)$ \\
During quarrying (D.Q.) & $17(101)$ \\
Rehabilitated & $18(77)$ \\
$\quad$ after operating $(<5$ years $)$ & $34(164)$ \\
$\quad$ after operating $(5$ years $<<10$ years $)$ & $37(211)$
\end{tabular}

Industrial, commercial and units (I.C.)

Residential urban area (R.U.)

Discontinuous artificial surfaces (D.A.)

Urban park (U.P.)

Vineyards and orchards (V.O.)

Arable land (A.L.)

Heterogeneous agricultural areas (H.A.)

Scrub and heathland (S.H.)

Dry grassland (D.G.)

Coniferous forest (C.F.)

Broad-leaved forest (B.F.)

Mixed forest (M.F.)

Waterway (W.)

Small water courses (S.W.),

Bodies of water (B.W.)

Table 2. Results of the modelling of bat activity's variation across gravel-sand pit life's cycle. 758

\begin{tabular}{lccc} 
& Chisq & df & $p$ \\
\hline gravel-sand pits state & 18.259 & 4 & 0.001 \\
temperature & 14.139 & 1 & $<0.001$ \\
season & 0.560 & 1 & 0.454 \\
year & 4.394 & 4 & 0.355
\end{tabular}


Appendix A: Detailed information on relationship between state of extraction or

Local characteristics of gravel-sand pits have been defined in two ways: (i) as a categorical variable with four categories of gravel-sand pit state (during quarrying and three categories of rehabilitation according to the time elapsed after operating ( $<5$ years; 5 years $<<10$ years and $>10$ years)) and (ii) as a categorical variable with five categories of vegetation (bare soil, seminatural grassland, bush (shrubs smaller than $7 \mathrm{~m}$ ), woodland (trees taller than $7 \mathrm{~m}$ ), water bodies (with water present predominantly over the year)) or

Table S1: Distribution of number sampled site according to their local characteristics

\begin{tabular}{lccccc}
\hline & bush & $\begin{array}{c}\text { water } \\
\text { bodies }\end{array}$ & woodland & $\begin{array}{l}\text { semi-natural } \\
\text { grassland }\end{array}$ & bare soil \\
\hline during quarrying & 4 & 6 & 0 & 15 & 70 \\
$\begin{array}{l}\text { after operating } \\
\begin{array}{l}(<5 \text { years }) \\
\text { after operating }\end{array}\end{array}$ & 0 & 30 & 0 & 39 & 8 \\
$\begin{array}{l}(5 \text { years }<<10 \text { years }) \\
\begin{array}{l}\text { after operating } \\
(>10 \text { years })\end{array}\end{array}$ & 11 & 100 & 31 & 68 & 2 \\
\hline
\end{tabular}

According to Pearson's Chi-squared test with p-values computed by Monte Carlo simulation (based on 2000 replicates) local characteristics (i.e. vegetation type or gravel-sand pit state) are nonindependent $(\mathrm{X}$-squared $=379.59, \mathrm{df}=\mathrm{NA}, \mathrm{P}$-value $=0.0005)$. 
The data were provided by the French national bat-monitoring program, a citizen science Program. Volunteer-based standardized monitoring schemes have been widely implemented in Europe and North America. In France, the National Museum of Natural History launched a Citizen Science Program 'Vigie-Nature’ (MNHN, 2012) with the Breeding Bird Survey, first program initiated in 1989 before extending this scheme to many other taxa such as the French Bat Monitoring Program (FBMP) which is based on standardized recordings echolocation bat calls. The latter scheme was launched in 2006. The objective of the scheme is to provide information on bat population trends and distributions in France. Such monitoring schemes have already revealed new information on bat population's trend like the Ireland monitoring (Roche et al. 2011). The FBMP include two different versions of protocol: road survey by car and count point. For comparison with the ROSELIERE program we have used data from the first protocol of the FBMP (i.e. count point protocol) as external data.

\section{Sampling design}

The protocol consists of a square of $2 \mathrm{~km}$-side randomly chosen (by the Museum) in a radius of $10 \mathrm{~km}$ from the observer's home, (i.e. on average one square randomly chosen between 80 possible squares) within which ten points are chosen by the observer with at least five points representative of the habitats of the square, the other being located in 'favourable' places for bats such as river banks and wood edges, etc. These sampling design allowed to obtain a quite good correlation between proportion of habitat sampled and proportion of habitat existing at the national scale $\left(\mathrm{R}^{2}=0.95\right)$, except for urban areas which were slightly more represented in our sampling. 
Figure S1-2: Selection of sampling site and recording points

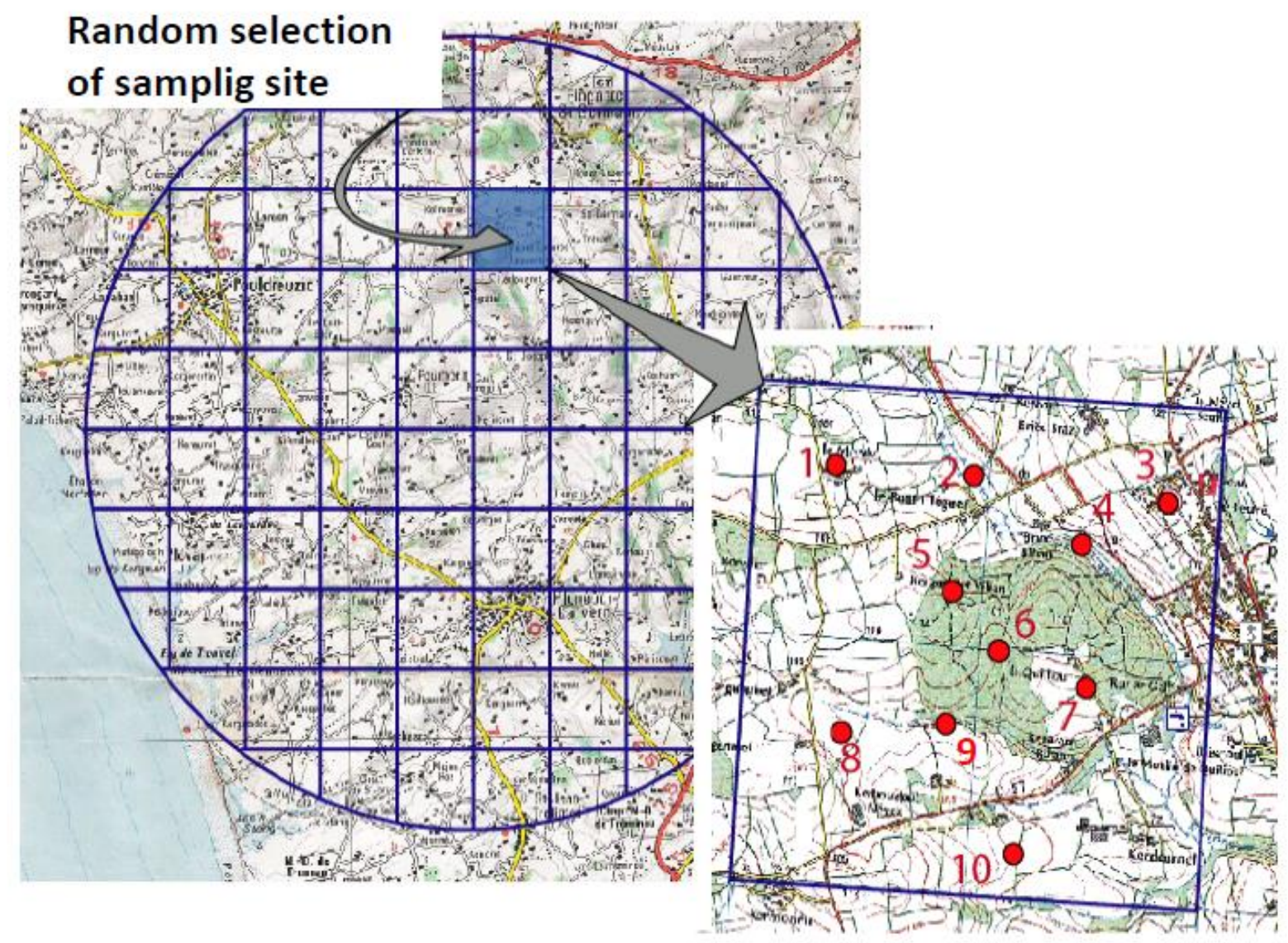

803

804

805

Figure S1-2: Map of the distribution in France of the count point sites from the French Bat

Monitoring Program (2006-2015).

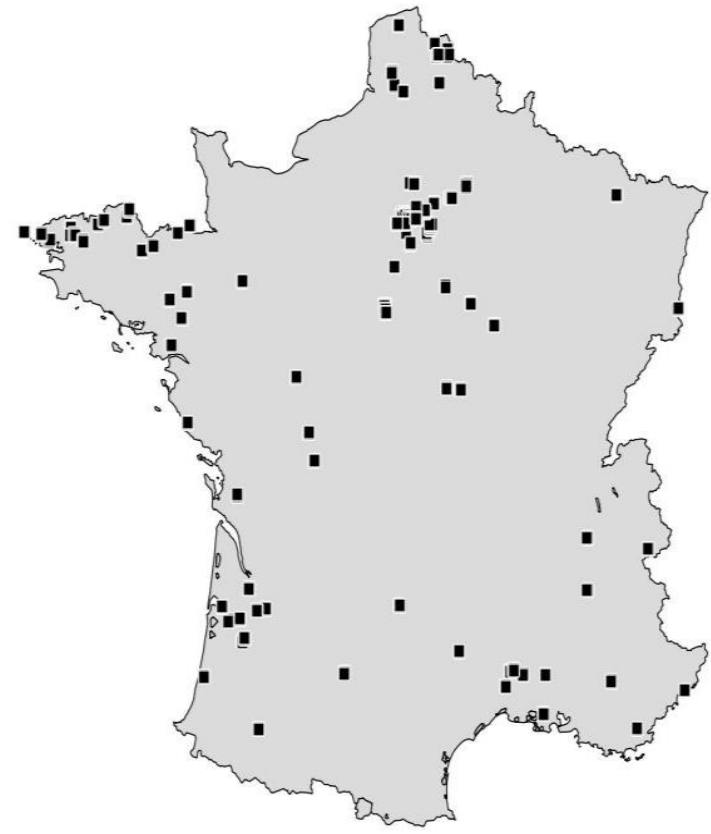




\section{Recording characteristic}

Bats calls were detected using a Tranquility Transect Bat detector (Courtpan Design Ltd, UK) and D240x (Pettersson Elektronik) and recorded on a Zoom H2 digital recorder (Samson technologies, USA). The time expansion was set to ten and sensitivity levels were set to enable the detection of echolocation calls while minimizing background noise due to wind or insects. Before used, all detectors are calibrated at the French National Museum History in order to obtain the same level of sensibility. Signal from the condenser microphone of the bat detector was internally amplified and high pass filtered with a $5 \mathrm{kHz}$ corner frequency and fed to the Zoom H2 which recorded it at 96000 sample/s as PCM files. Sound was stored on Secured Card in Waveform Audio File Format more commonly known as WAV format, more commonly known as WAV format, a format without compression. Tranquility Transect set to record $1.28 \mathrm{~s}$ of sound at x10 time expansion. Each recorded $1.28 \mathrm{~s}$ is followed by $12.8 \mathrm{~s}$ of playback, during which time the detector does not record. All ultrasound detectors were previously calibrated by the French National Museum of Natural History in order to have the trigger level.

\section{LITTERATURE CITED}

Roche, N., Langton, S., Aughney, T., Russ, J.M., Lynn, D., Catto, C. 2011. A car-based monitoring method reveals new information on bat populations and distributions in Ireland. Anim. Conserv. 14, 642-651. 


\section{Appendix C: Bats identifications}

Identifications were made by voluntary observers and then validated by Museum's scientists. The majority of volunteers involved in the bat monitoring had participated in training courses organized since 2007, allowing high homogeneity in the identification criteria We used Syrinx software version 2.6 (Burt, 2006) for spectrogram and Adobe Audition for spectral analysis and in complement we also used Scan'R (Binary Acoustic Technology, 2010) to isolate each bat vocalization and automate measure of relevant parameters (Gannon et al., 2004, Obrist et al., 2004, Barataud 2012).

Identification was made at the species level except for two genera: Plecotus sp. for which there is a lack of consensus about the acoustic criteria to use for identification at the species level (Russ, 1999; Obrist et al., 2004; Barataud, 2012) and Myotis sp. because of the very low occurrence of each single Myotis species and some uncertainties on acoustic identification at the species level (Obrist et al., 2004; Barataud, 2012). Note that the Plecotus and the Myotis group primarily included species considered to be gleaners, which capture the majority of their prey from substrates in cluttered environments (Arlettaz et al., 2001). These species eat mainly diurnal Brachyceran Diptera and non-volant arthropods such as weevils, lepidopteran larvae, harvestmen and spiders (Audet 1990; Swift and Racey, 2002; Dietz et al., 2007), while the "aerial hawking bats", that include Pipistrellus, Eptesicus serotinus and Nyctalus species, mainly search the sky for prey (Schnitzler et al. 2003 Holderied, \& von Helversen, 2003).

The main relevant parameters used were:

- Call duration (msec)

- Time elapsed since previous detection (msec)

- Maximum frequency detected (Fmax, KHz)

- Minimum frequency detected (Fmin, KHz)

- Total Bandwidth [Fmax - Fmin] (KHz)

- Frequency at strongest sound pressure level $(\mathrm{KHz})$

- Location of Dominant Frequencies (\% of total duration)

- High end of characteristic $(\mathrm{KHz})$

- Low end of characteristic $(\mathrm{KHz})$

- Global slope of the call (KHz per msec)

- Time of the heel or High Fc (percent of duration)

- Upper slope [start to High Fc] (KHz per msec)

- Lower slope [High Fc to Low Fc] (KHz per msec)

- Fundamental frequency $(\mathrm{KHz})$

- 2nd harmonic frequency $(\mathrm{KHz})$

- Curvature measurement as a way to characterize the shape of bat calls (see Jolly 1997)Curve fit error parameter; a measurement of how much error exists between the curvature model and the actual shape of the call 


\section{Composition of group non-identified at the species level}

Myotis species (Myotis alcathoe, Myotis daubentonii, Myotis emarginatus, Myotis brandtii /mystacinus, and Myotis nattereri) were pooled because of the very low occurrence of each single Myotis species and some uncertainties on acoustic identification at the species level (Obrist et al., 2004; Barataud, 2012). In addition, due to some overlap between acoustic repertoires of the pair P. kuhlii and P. nathusii or for the pair Eptesicus serotinus and Nyctalus leisleri and for the pair Pipistrellus pipistrellus and Pipistrellus nathusii it was not possible to assign the exact species with certainty respectively for $36.5 \%, 10.2 \%$ and $0.1 \%$ of calls. For more details on the composition of each group, see Supplementary material 2.

Table S2: Species detected and number of contact

* indicates species of the Annexe II of the EU Habitats Directive (EEC 1992), VU indicates species listed as vulnerable in the French mammal red list IUCN (UICN France et al. 2009)

\begin{tabular}{lcc}
\hline Species & Gravel-sand pit & FBMP \\
\hline Vespertilionidae & 1 & 0 \\
Myotis alcathoe & 1 & 0 \\
Myotis brandtii/mystacinus & 0 & 19 \\
Myotis nattereri & 2 & 0 \\
Myotis emarginatus* & 40 & 394 \\
Myotis daubentoni & 86 & 410 \\
Myotis sp. & 130 & 823 \\
Myotis ssp. total & 0 & 24 \\
Nyctalus lasiopterus & 132 & 366 \\
Nyctalus leisleri & 104 & 597 \\
Nyctalus noctula & 27 & 247 \\
Eptesicus serotinus & 27 & 566 \\
Pipistrellus kuhlii & 88 & 286 \\
Pipistrellus nathusii & 910 & 8099 \\
Pipistrellus pipistrellus & 0 & 16 \\
Pipistrellus pygmaeus & 0 & 1 \\
Hypsugo savi & 4 & 7 \\
Plecotus ssp. & 0 & 21 \\
Barbastella barbastellus & \\
Miniopteridae & 0 & 1 \\
Miniopterus schreibersi* ${ }^{*}$, VU & & \\
Rhinolophidae & 0 & 3 \\
Rhinolophus ferrumequinum* & 0 & \\
Rhinolophus hipposideros & & \\
\hline
\end{tabular}


Table S3: Comparisons between observed values of bat activities in this study and those from the whole dataset of the $\mathrm{FBMP}^{1}$. FBMP values were divided per 10 according to the sampling design of the FBMP (10 points per square) in order to be compatible with value of our study provided at the level of the point. Q25\% is the value that cuts off the first $25 \%$ of the whole FBMP data when it is sorted in ascending order. Q75\% is the value that cuts off the first $75 \%$, Q98\% is the value that cuts off the first $98 \%$. We considered bat activity value between Q25\% and Q75\% as moderate, value upper than Q75\% high value of bat activity and upper to 98\% very high value of bat activity.

\begin{tabular}{lllll}
\hline Bat activity & This study & \multicolumn{3}{c}{ National } \\
\hline Species & & $Q 25 \%$ & $Q 75 \%$ & $Q 98$ \\
\hline Eptesicus serotinus & 0.092 & 0.1 & 0.4 & 2.2 \\
Myotis spp & 0.320 & 0.3 & 1.5 & 10 \\
Nyctalus leisleri & 0.167 & 0.2 & 0.7 & 4.2 \\
Nyctalus noctula & 0.236 & 0.1 & 0.8 & 2.5 \\
Pipistrellus kulhii & 0.199 & 0.3 & 2 & 7.1 \\
Pipistrellus nathusius & 0.126 & 0.1 & 0.4 & 4.4 \\
Pipistrellus pipistrellus & 3.029 & 1.3 & 5.9 & 11.9 \\
\hline
\end{tabular}

\footnotetext{
${ }^{l}$ http://vigienature.mnhn.fr/sites/vigienature.mnhn.fr/files/uploads/R\%C3\%A9f\%C3\%A9rentielsVC.pdf
}

\section{LITTERATURE CITED}

Audet, D., 1990. Foraging behavior and habitat use by a gleaning bat, Myotis myotis (Chiroptera : Vespertilonidae). J. Mammal. 71, 420-427.

Barataud, M., 2012. Ecologie acoustique des chiroptères d'Europe. Identification des espèces, études de leurs habitats et comportements de chasse. Biotope, Mèze; Muséum national d'histoire naturelle, Paris (collection Inventaires et biodiversité), 344 p.

Dietz, C., von Helversen, O., Nill, D., 2009. L'encyclopédie des chauves-souris d'Europe et d'Afrique du Nord : Biologie, caractéristiques, protection. Delachaux et Niestlé, Paris, France. 400 p.

Gannon, W.L., O’Farell, M.J., Corben, C., Bedrick, E., 2004. Call character Lexicon and analysis of field recorded bat echolocation calls. Echolocation in bats and dolphinsEdited by J.A. Thomas, CF Moss, and Vater. 2004. University of Chicago Press, Chicago, IL, USA, 604 pp.

Holderied, M. W., von Helversen, O., 2003. Echolocation range and wingbeat period match in aerial-hawking bats. P Phys. Soc. Lond. B 270, 2293-2299.

UICN France, MNHN, SFEPM \& ONCFS (2009). La Liste rouge des espèces menacées en France - Chapitre Mammifères de France métropolitaine. Paris, France [https://www.uicn.fr/IMG/pdf/Tableau_Liste_rouge_Mammiferes_de_metropole.pdf] 
Obrist, M.K., Boesch, R., Flückiger, P.F., 2004. Variability in echolocation call design of 26 Swiss bat species: consequences, limits and options for automated field identification with a synergetic pattern recognition approach. Mammalia 68 ,(4), 307-322.

Russ, J. 1999. The bats of Britain and Ireland. Echolocation calls, sound analysis and species identification. Alana Books, Bishop's Castle, United Kingdom.

Schnitzler, H.U., Moss, C.F., Denzinger, A., 2003. From spatial orientation to food acquisition in echolocating bats. Trends in Ecology \& Evolution 18, 386-394.

Swift, S., Racey, P., 2002. Gleaning as a foraging strategy in Natterer's bat Myotis nattereri Behav. Ecol. Sociobiol. 52(5), 408-416 
Appendix D: Assessment of Habitat Specialization species index and community specializations indices

Habitat Specialization species index were assessed using data provided by the car transect survey, the second protocol of the French Bat Survey (for additional information on this protocol, see Azam et al. 2016).

\section{French Bat Survey.}

Volunteer-based standardized monitoring schemes have been widely implemented in Europe and North America (Jiguet et al., 2012). In France, the National Museum of Natural History (MNHN) initiated the French Bat Monitoring Program (FBMP) in 2006. This scheme offers a dataset of 6774 sites with both habitat characterizations and bat identifications ( 28 species and 960500 bat calls).

\section{Counting methods}

The FBMP offers keen volunteers to count bats twice a year: once during the period 15th June to 31 st July, and a second time during the period 15th August to 31st September. Two different versions are proposed: count point and road survey by car. We used the road survey method to assess the Specialization species index (SSI). The choice of the road circuit is delegated to the volunteers because the main constraint is related to their safety. The circuit must be done at night at low speed (recording at constant speed: $30 \pm 5 \mathrm{~km} / \mathrm{h}$ ), this excludes non paved roads, roads with a lot of traffic and high-speed roads. Only volunteers with their local knowledge of the field are able to identify such roads. All roads are thus of similar width, around 10 meters. Observers were asked to choose a road circuit of at least $30 \mathrm{~km}$ and located in a $10 \mathrm{~km}$ radius around their house. The circuit must not overlap itself. The second requirement is to design a circuit which crosses, as much as possible, the different habitats present in the area proportionally to their representativeness. To avoid biases in habitat sampling (we assume that observers would tend to follow rich habitats), the MNHN validates the circuit and defines randomly a starting point. Starting from this point, the circuit is divided into ten $2-\mathrm{km}$ road segments, separated by $1-\mathrm{km}$ road segments in which no recording is done. This sampling design allows to obtain a quite good correlation between proportion of habitat sampled and proportion of habitat existing at the national scale $\left(\mathrm{R}^{2}=0.94\right)$, except for urban areas which were slightly more represented in our sampling. 


\section{Assessment of specializations indices}

In the French national bat monitoring volunteers were involved in collecting habitat variable on a detailed and adapted basis. Habitat information is recorded on the first reconnaissance visit to the circuit. The appropriate habitat codes are chosen from an established hierarchical system allowing to describe more than 950 habitat types, which is very similar to widely used habitat code in bird monitoring schemes (see Crick 1992), but adapted to take account of bat foraging specifics and particularly linear element (for more details about the French Bat monitoring see the website [http://vigienature.mnhn.fr/page/releves-d-habitats]). Habitat classes are collected in a radius of $100 \mathrm{~m}$ around the sampled point ( 5 points spaced out by 400 $\mathrm{m}$ for each 2-km segment) and grouped into 18 classes in order to obtain sufficient number of sample per class (for more methodological information see Julliard et al., 2006; Kerbiriou et al. 2010).

\section{Specialization species index (SSI)}

We quantified the species specialization index (SSI), which is the degree of habitat specialization for a species, as the coefficient of variation (SD/mean) of its densities across habitats following Julliard et al.'s approach (2006). SSI is thus independent to species habitat preferences. However, it is also possible to assess the species specialization to forest habitats by calculating the average density of a species inventoried in forest habitats divided by the average density in non-forest habitats.

Table S4: Habitat Specialization Index

\begin{tabular}{lc}
\hline Bat species & Habitat Specialization Index \\
\hline Barbastella barbastellus & 3.64 \\
Eptesicus serotinus & 1.50 \\
Myotis myotis & $\mathrm{NA}$ \\
Myotis daubentonii & 3.48 \\
Myotis mystacinus & 3.86 \\
Myotis nattereri & 2.40 \\
Nyctalus leisleri & 0.95 \\
Nyctalus noctula & 1.58 \\
Pipistrellus kuhlii & 0.75 \\
Pipistrellus nathusii & 3.06 \\
Pipistrellus pipistrellus & 0.54 \\
Pipistrellus pygmaeus & 1.79 \\
Plecotus sp (mainly austriacus) & 1.36 \\
Rhinolophus hipposideros & $\mathrm{NA}$ \\
\hline
\end{tabular}


Assessment of bat community specializations indices

The Community Specialisation Index (CSI) is calculated as the arithmetic mean of the species specialization index (SSI) of the species detected, weighted by the abundances (Julliard et al., 2006):

$\mathrm{CSI}_{\mathrm{j}}=\frac{\sum_{\mathrm{i}=1}^{\mathrm{n}} a_{\mathrm{ij}}\left(\mathrm{SSI}_{\mathrm{i}}\right)}{\sum_{\mathrm{i}=1}^{\mathrm{n}} a_{\mathrm{ij}}}$

where $n$ is the total number of species recorded, $a_{i j}$ is the abundance of individuals of species $i$ (with a SSI specialization index) in segment j (Devictor et al., 2008).

The CSI reflects the relative abundance of more or less specialized species in local assemblages and is therefore expected to decrease following the relative declines of specialists (species with a high SSI). For the analyse, we kept only sites with a non-null abundance because a null CSI does not describe a generalist community.

\section{LITTERATURE CITED}

Azam, C., Le Viol, I., Julien, J.F., Bas, Y., Kerbiriou, C. 2016. Disentangling the relative effect of light pollution, impervious surfaces and intensive agriculture on bat activity with a national-scale monitoring program. Landscape Ecol. 31(10), 2471-2483.

Barataud, M. 2012. Ecologie acoustique des chiroptères d'Europe. Identification des espèces, études de leurs habitats et comportements de chasse. Biotope, Mèze; Muséum national d'histoire naturelle, Paris (collection Inventaires et biodiversité), 344 p.

Crick, H.Q.P. 1992. A bird-habitat coding system for use in Britain and Ireland incorporating aspects of land-management and human activity. Bird Study 39, 1-12

Freckleton, R.P. 2002. On the misuse of residuals in ecology: regression of residuals vs. multiple regression. J. Anim. Ecol. 71, 542-545.

Jiguet, F., Devictor, V., Julliard, R., Couvet, D. 2012. French citizens monitoring ordinary birds provide tools for conservation and ecological sciences. Acta Oecol. 44, 58-66.

Julliard, R., Clavel, J., Devictor, V., Jiguet, F., Couvet D. 2006. Spatial segregation of specialists and generalists in bird communities. Ecol. Let. 9, 1237-1244.

Kerbiriou, C., Bas, Y., Dufrêne, L., Robert, A., Julien, JF. 2010. Long term trends monitoring of bats, from biodiversity indicator production to species specialization assessment. Society for Conservation Biology - 24th Annual Meeting, 3 - 7 July, 2010, Edmonton, Alberta, Canada.

Marnell, F., Presetnik, F.P. 2010. Protection of over ground roosts for bats. EUROBATS Publication Series No 4. UNEP/EUROBATS Secretariat, Bonn, Germany. 
Table S5: Selection between 4 models: GLMM with Poisson distribution, with negative binomial distribution, zero inflation model with Poisson distribution or zero inflation model with negative binomial distribution. When modelling of abundance did not fit well, we transformed the response variable (i.e. bat activity abundance) in a presence/absence variable and then used a GLMM with a binomial error distribution, this was only the case for Eptesicu serotinus.

Choice and validation of model were based on a multi-criteria approach following Zuur et al. (2009) looking at pattern in residual, value of AIC (Burnham and Anderson. 2002) and pseudo R-square. NC indicates that GLMM did not converge (package used: glmmADMB), as AIC were assessed using glmmPQL, NA indicates that glmmPQL did not converge. Selected models are given in bold letters.

1030

1031

\section{Litterature cited} and Extensions in Ecology with R. Statistics for Biology and Health. Springer, New York, USA, p. 574. 
Appendix F: Average occurrence and bat activity among the different gravel-sand pit state and habitat

\begin{tabular}{|c|c|c|c|c|c|c|c|c|c|c|c|c|c|c|}
\hline & $\begin{array}{l}\text { E. serotinus } \\
\text { occurrence } \\
\end{array}$ & bat activity & $\begin{array}{l}\text { Myotis spp } \\
\text { occurrence }\end{array}$ & bat activity & $\begin{array}{l}\text { N. leisleri } \\
\text { occurrence }\end{array}$ & bat activity & $\begin{array}{l}\text { N. noctula } \\
\text { occurrence } \\
\end{array}$ & bat activity & $\begin{array}{l}\text { P. kulhii } \\
\text { occurrence }\end{array}$ & bat activity & $\begin{array}{l}\text { P. nathusius } \\
\text { occurrence } \\
\end{array}$ & bat activity & $\begin{array}{c}\text { P. pipistrellus } \\
\text { occurrence } \\
\end{array}$ & bat activity \\
\hline \multicolumn{15}{|l|}{ Gravel-sand pit } \\
\hline Before operating (B.O.) & 0.013 & 0.038 & 0.013 & 0.019 & 0.082 & 0.165 & 0.038 & 0.139 & 0.006 & 0.006 & 0.013 & 0.013 & 0.203 & 0.494 \\
\hline During quarrying (D.Q.) & 0.010 & 0.010 & 0.059 & 0.099 & 0.020 & 0.020 & 0.040 & 0.059 & 0.059 & 0.079 & 0.050 & 0.059 & 0.356 & 0.822 \\
\hline \multicolumn{15}{|l|}{ Rehabilitated } \\
\hline after operating ( $<5$ years) & 0.013 & 0.026 & 0.143 & 0.169 & 0.078 & 0.104 & 0.065 & 0.065 & 0.039 & 0.039 & 0.052 & 0.091 & 0.390 & 1.169 \\
\hline after operating $(5$ years $<<10$ years $)$ & 0.024 & 0.061 & 0.073 & 0.104 & 0.067 & 0.146 & 0.067 & 0.116 & 0.012 & 0.012 & 0.067 & 0.079 & 0.396 & 1.451 \\
\hline after operating $(>10$ years $)$ & 0.014 & 0.038 & 0.133 & 0.412 & 0.081 & 0.341 & 0.081 & 0.246 & 0.033 & 0.062 & 0.076 & 0.284 & 0.412 & 1.995 \\
\hline \multicolumn{15}{|l|}{ FBMP points } \\
\hline Industrial, commercial and units (I.C.) & 0.000 & 0.000 & 0.000 & 0.000 & 0.000 & 0.000 & 0.000 & 0.000 & 0.042 & 0.083 & 0.125 & 0.167 & 0.417 & 1.042 \\
\hline $\begin{array}{l}\text { Residential urban area (R.U.) } \\
\text { Discontinuous artificial surfaces }\end{array}$ & 0.007 & 0.009 & 0.007 & 0.045 & 0.020 & 0.025 & 0.029 & 0.165 & 0.038 & 0.205 & 0.016 & 0.089 & 0.342 & 2.254 \\
\hline (D.A.) & 0.086 & 0.160 & 0.056 & 0.074 & 0.123 & 0.660 & 0.086 & 0.383 & 0.136 & 0.469 & 0.019 & 0.049 & 0.574 & 4.377 \\
\hline Urban park (U.P.) & 0.005 & 0.005 & 0.010 & 0.015 & 0.000 & 0.000 & 0.019 & 0.388 & 0.024 & 0.238 & 0.005 & 0.015 & 0.388 & 2.354 \\
\hline Vineyards and orchards (V.O.) & 0.250 & 0.333 & 0.000 & 0.000 & 0.125 & 0.250 & 0.000 & 0.000 & 0.375 & 0.792 & 0.083 & 0.083 & 0.250 & 0.875 \\
\hline Arable land (A.L.) & 0.031 & 0.092 & 0.043 & 0.074 & 0.043 & 0.166 & 0.043 & 0.282 & 0.031 & 0.055 & 0.012 & 0.018 & 0.313 & 1.583 \\
\hline $\begin{array}{l}\begin{array}{l}\text { Heterogeneous agricultural areas } \\
\text { (H.A.) }\end{array} \\
\text { a }\end{array}$ & 0.036 & 0.040 & 0.053 & 0.146 & 0.016 & 0.036 & 0.008 & 0.008 & 0.105 & 0.401 & 0.020 & 0.126 & 0.470 & 3.174 \\
\hline Scrub and heathland (S.H.) & 0.037 & 0.074 & 0.074 & 0.407 & 0.000 & 0.000 & 0.000 & 0.000 & 0.000 & 0.000 & 0.000 & 0.000 & 0.556 & 1.889 \\
\hline Dry grassland (D.G.) & 0.000 & 0.000 & 0.077 & 1.154 & 0.077 & 0.154 & 0.038 & 0.077 & 0.154 & 0.269 & 0.000 & 0.000 & 0.346 & 4.154 \\
\hline Coniferous forest (C.F.) & 0.367 & 1.367 & 0.000 & 0.000 & 0.267 & 0.933 & 0.000 & 0.000 & 0.400 & 0.667 & 0.000 & 0.000 & 0.367 & 2.900 \\
\hline Broad-leaved forest (B.F.) & 0.037 & 0.086 & 0.081 & 0.321 & 0.066 & 0.213 & 0.026 & 0.114 & 0.029 & 0.042 & 0.007 & 0.007 & 0.420 & 2.563 \\
\hline Mixed forest (M.F.) & 0.113 & 0.375 & 0.013 & 0.013 & 0.075 & 0.188 & 0.025 & 0.075 & 0.113 & 0.425 & 0.013 & 0.013 & 0.350 & 3.713 \\
\hline Waterway (W.) & 0.000 & 0.000 & 0.108 & 1.500 & 0.014 & 0.054 & 0.014 & 0.027 & 0.054 & 0.203 & 0.054 & 0.081 & 0.446 & 5.081 \\
\hline Small water courses (S.W.), & 0.125 & 0.250 & 0.232 & 1.232 & 0.054 & 0.089 & 0.054 & 0.143 & 0.071 & 0.250 & 0.036 & 0.143 & 0.571 & 7.339 \\
\hline Large water courses (L.W.) & 0.000 & 0.000 & 0.063 & 0.063 & 0.021 & 0.063 & 0.083 & 2.854 & 0.083 & 0.646 & 0.063 & 0.083 & 0.417 & 3.500 \\
\hline Ponds (P.) & 0.000 & 0.000 & 0.028 & 0.028 & 0.000 & 0.000 & 0.056 & 2.528 & 0.139 & 0.722 & 0.028 & 0.028 & 0.306 & 2.194 \\
\hline Bodies of water (B.W.) & 0.076 & 0.363 & 0.280 & 2.344 & 0.096 & 0.318 & 0.051 & 0.223 & 0.083 & 0.344 & 0.083 & 1.096 & 0.669 & 13.146 \\
\hline Average & 0.057 & 0.151 & 0.070 & 0.373 & 0.060 & 0.178 & 0.037 & 0.359 & 0.092 & 0.273 & 0.037 & 0.115 & 0.407 & 3.094 \\
\hline
\end{tabular}


1040 Appendix G: Pairwise comparisons between habitats.

1041 We computed least-squares means for specified factors (i.e. habitats) in our GLMM and ran comparisons among them using package lsmeans,

1042 Lenth R. V. 2015

1043 Table S6: Groups of significant pairwise comparisons between habitats

\begin{tabular}{|c|c|c|c|c|c|c|c|c|c|c|}
\hline Habitat & P. pipistrellus & P. kuhlii & P. nathusii & N. noctula & N. leisleri & E. serotinus & Myotis ssp. & Richness & Abundance & CSI \\
\hline Before operating & 1 & all group & 1234567890ABCDE & 1234567890ABCDEF & $1234567890 \mathrm{AB}$ & $1234567890 \mathrm{~A}$ & $1234567890 \mathrm{ABCD}$ & 1 & 1 & 1 \\
\hline During quarrying & 123 & 2345680ABCGHIJK & 1234567890ABCDE & $460 \mathrm{~A}$ & 470 & 123479 & $1 \mathrm{E}$ & 12 & 12 & 1 \\
\hline After operating ( $<5$ years) & 123 & $30 \mathrm{H}$ & $5678 \mathrm{E}$ & 789BCDEF & $9 \mathrm{~B}$ & 234568 & $\mathrm{C}$ & 12 & 12 & 1 \\
\hline After operating ( 5 years $<<10$ years $)$ & 123 & $17 \mathrm{~F}$ & $56780 \mathrm{ABCDE}$ & 80ACDF & $57890 \mathrm{AB}$ & 3468 & $67 \mathrm{~A}$ & 12 & 12 & 1 \\
\hline After operating ( $>10$ years) & 123 & $28 \mathrm{G}$ & $9 \mathrm{DE}$ & 4679BE & $0 \mathrm{AB}$ & 25 & C & 2 & 12 & 1 \\
\hline Industrial, commercial and units & 123 & 345690ABCDEHIJKLMNOPQ & $9 \mathrm{DE}$ & 1234567890ABCDEF & $1234567890 \mathrm{AB}$ & $1234567890 \mathrm{~A}$ & $\begin{array}{c}1234567890 \mathrm{ABCD} \\
\mathrm{E} \\
\end{array}$ & 12 & 12 & 1 \\
\hline Residential urban area & 123 & 1234567890ABCDELNO & 12349 & 134780BD & $1234567890 \mathrm{AB}$ & $1234567890 \mathrm{~A}$ & $\begin{array}{c}1234567890 \mathrm{ABCD} \\
\mathrm{E} \\
1234567890 \mathrm{BCD}\end{array}$ & 12 & 12 & 1 \\
\hline Discontinuous artificial surfaces & 23 & FGHIJKMPQ & $1245680 \mathrm{AC}$ & 2569ACEF & $1234567890 \mathrm{AB}$ & $1234567890 \mathrm{~A}$ & $\underset{\mathrm{E}}{123456780 \mathrm{ABCD}}$ & 2 & 12 & 1 \\
\hline Urban park & 123 & 69СEKM & $1235670 \mathrm{AB}$ & 35 & $1234567890 \mathrm{AB}$ & 1 & 1 & 12 & 12 & 1 \\
\hline Vineyards and orchards & 123 & DLNOPQ & 379BDE & 1234567890ABCDEF & $1234567890 \mathrm{AB}$ & $790 \mathrm{~A}$ & $\begin{array}{c}1234567890 \mathrm{ABCD} \\
\mathrm{E}\end{array}$ & 12 & 12 & 1 \\
\hline Arable land & 12 & $1234569 \mathrm{DN}$ & $2367 \mathrm{AB}$ & 2569ACEF & 47 & 2356 & 23 & 12 & 12 & 1 \\
\hline Heterogeneous agricultural areas & 123 & 780ABCEFGHIJKLMOPQ & 1234567890ABCDE & 1234567890ABCDEF & 1246 & 3468 & $\begin{array}{c}450 \\
4024567009 B C D\end{array}$ & 12 & 12 & 1 \\
\hline Scrub and heathland & 123 & all group & 1234567890ABCDE & 1234567890ABCDEF & $1234567890 \mathrm{AB}$ & $1234567890 \mathrm{~A}$ & $\begin{array}{l}1234567890 \mathrm{ABCD} \\
\mathrm{E}\end{array}$ & 12 & 12 & 1 \\
\hline Dry grassland & 123 & $5 \mathrm{BJ}$ & $1234567890 \mathrm{ABCDE}$ & $34567890 \mathrm{AC}$ & $1234567890 \mathrm{AB}$ & $1234567890 \mathrm{~A}$ & $\begin{array}{l}\mathrm{OABCD} \\
1234567890 \mathrm{BBCD}\end{array}$ & 12 & 2 & 1 \\
\hline Coniferous forest & 123 & 9EM & $1234567890 \mathrm{ABCDE}$ & 1234567890ABCDEF & 25 & $5680 \mathrm{~A}$ & $\underset{\mathrm{E}}{123456780 \mathrm{ABCD}}$ & 12 & 12 & 1 \\
\hline Broad-leaved forest & 123 & 1234569DN & 150 & 1234567890ABCDEF & 470 & 123479 & $89 \mathrm{~B}$ & 12 & 12 & 1 \\
\hline Mixed forest & 123 & $4 \mathrm{AI}$ & 150 & 12 & 13 & 4780 & 12468 & 12 & 12 & 1 \\
\hline Waterway & 23 & all group & 1234567890ABCDE & 123456 & $1234567890 \mathrm{AB}$ & $1234567890 \mathrm{~A}$ & $234567890 \mathrm{ABC}$ & 12 & 2 & 1 \\
\hline Small water courses & 23 & 1234567890ABCDELNO & 123490ABCD & 1234567890ABCDEF & 35789 & $9 \mathrm{~A}$ & $\mathrm{D}$ & 2 & 2 & 1 \\
\hline Large water courses & 123 & NOQ & 1234567890ABCDE & 35 & $1234567890 \mathrm{AB}$ & $1234567890 \mathrm{~A}$ & 579 & 12 & 12 & 1 \\
\hline Ponds & 123 & DLP & 1234567890ABCDE & BDEF & $1234567890 \mathrm{AB}$ & $1234567890 \mathrm{~A}$ & 3579 & 12 & 12 & 1 \\
\hline Bodies of water & 3 & all group & $489 \mathrm{CDE}$ & 1234567890ABCDEF & $68 \mathrm{~A}$ & 4780 & E & 2 & 2 & 1 \\
\hline
\end{tabular}


Appendix H: Impact of taking into account or not P. pipistrellus (i.e. the most abundant species) on assessment of age of gravel-sand pits restoration effect on relative importance of bat activity

Fig. S2: Relative importance of bat activity in gravel-sand pits including $P$. pipistrellus among the species dataset (a) or without P. pipistrellus (b)

(a)

(b)
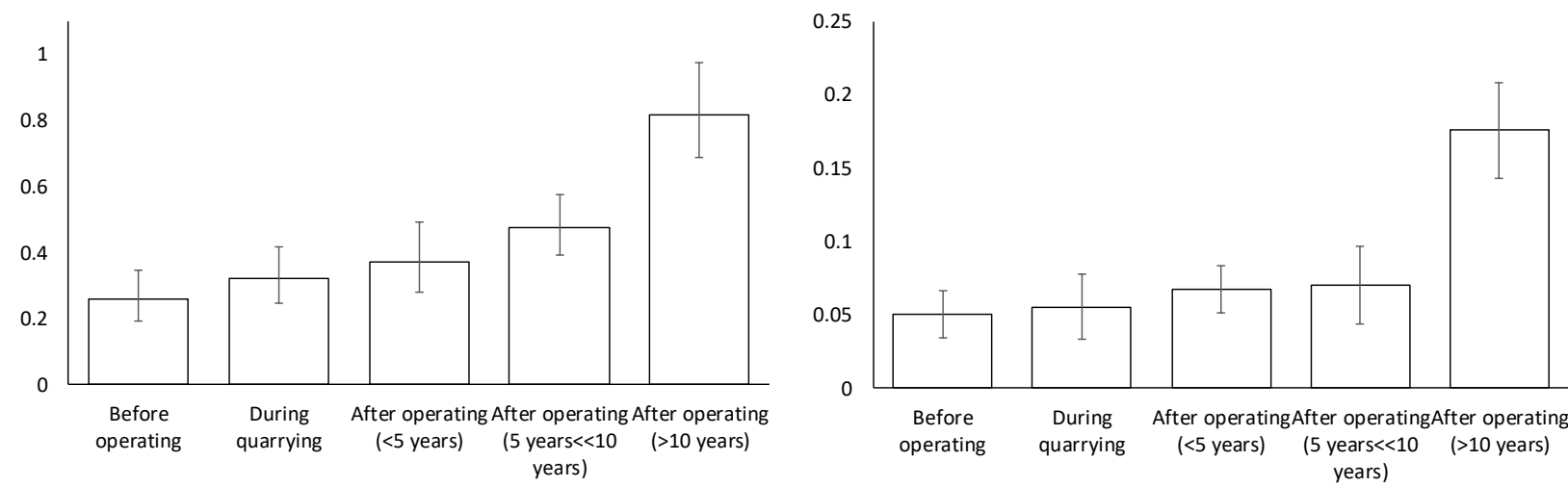

Table S7: Results of the modelling of bat activity's variation across gravel-sand pit life's cycle including or not $P$. pipistrellus

\begin{tabular}{llllllll}
\hline & \multicolumn{3}{l}{ with P. pipistrellus } & \multicolumn{3}{l}{ Without P. pipistrellus } \\
\hline & Chisq & df & $p$ & Chisq & df & $p$ \\
\hline gravel-sand pits state & 18.259 & 4 & 0.001 & 26.171 & 4 & $<0.001$ \\
temperature & 14.139 & 1 & $<0.001$ & 4.691 & 1 & 0.030 \\
season & 0.560 & 1 & 0.454 & 5.572 & 1 & 0.018 \\
year & 4.394 & 4 & 0.355 & 0.222 & 1 & 0.690 \\
autocovariate & 7.201 & 1 & 0.007 & 0.158 & 1 & 0.637 \\
\hline
\end{tabular}

